\title{
واقع تطبيق التسويق الداخلي في المؤسسات الخدمية بالجزائر حالة مؤسسة بريد الجزائر ـ قسنطينة ـ
}

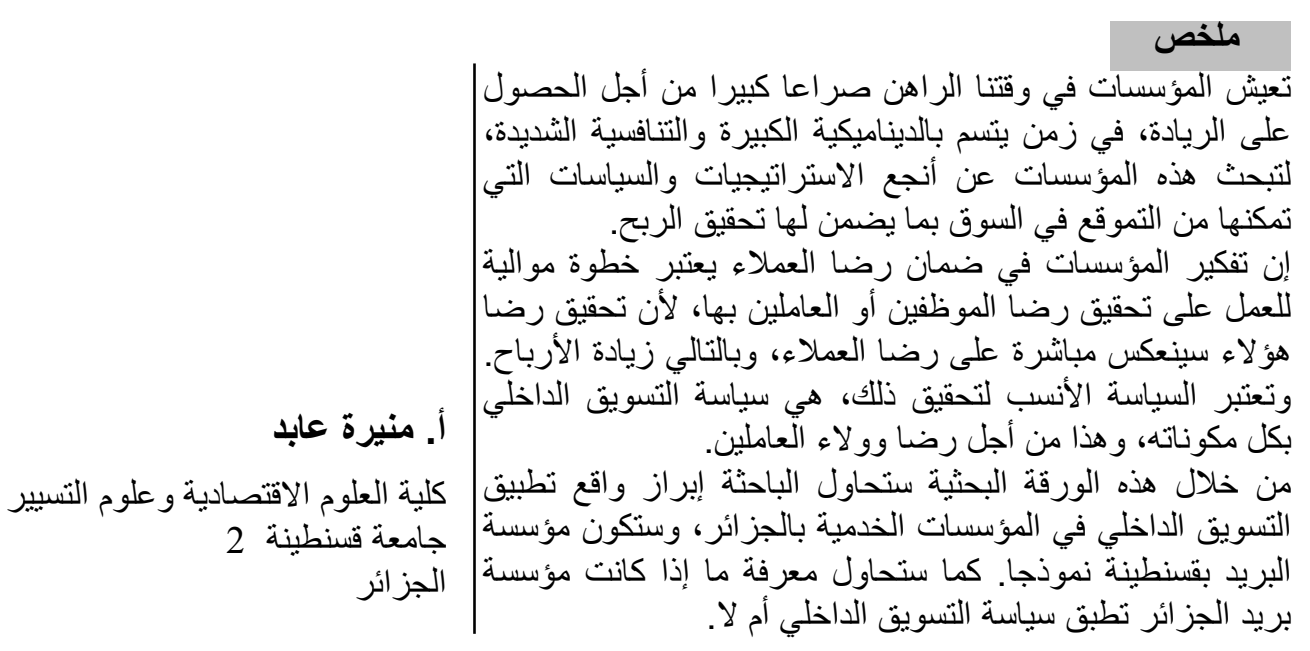

\section{Abstract}

Institutions living in our time have major conflicts in order to obtain the

عالم اليوم بتغيرات كثيرة ومعقدة، أدت إلى اشتثاد المنافسة واحتدامها بين

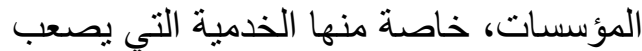

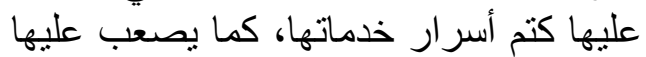

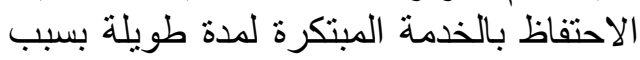

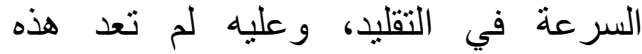
المؤسسات تتبع إستراتيجية و واحدة في فئي قيادتها، بل تعددت استراتيجياتها وتباينت،

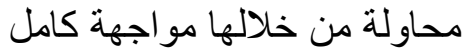
leadership, in a time which has a large dynamic behavior and huge competition, because these institutions are looking for the most effective strategies and policies that will enable them positioning in the market in order to ensure the achievement of its profit. The thinking institutions in ensuring customer satisfaction is a second step after work to achieve the satisfaction of their employees, because the Achieving Satisfaction of these will be 
الظروف التي تعترضها أثناء ممارسة نشاطها داخل سوق يتميز بالمنافسة الثديدة.

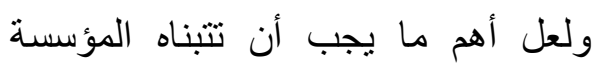

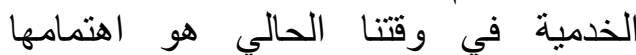
بالموظف قبل العميل، لأن الموظف هو الذي الذي العيل

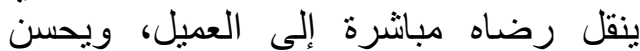

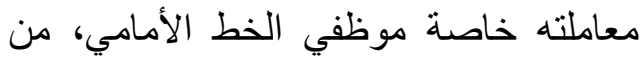

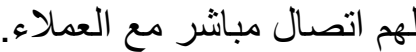

بالرضا الوظيفي، يكون من خلال تطبيق

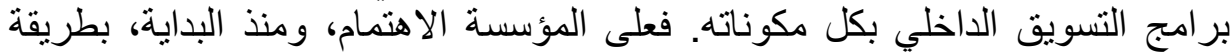

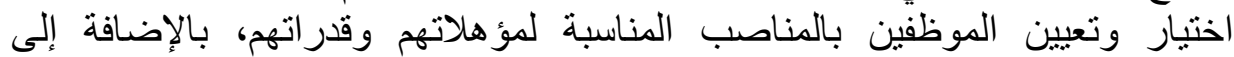

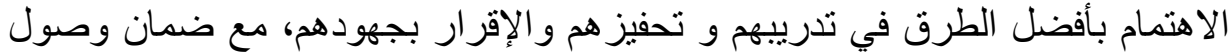

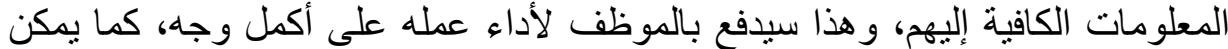
المؤسسة من تحقيق أهدافها.

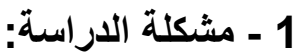

على ضوء ما تقدم، وبما أن المؤسسات تعمل على تحقيق تفاعل إيجابي بين

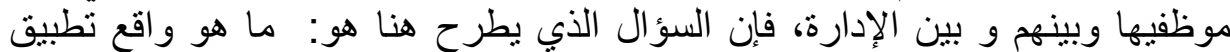
سياسة التسويق الداخلي بالمؤسسات الخدمية عموما وبمؤسئة الإنس بريد الجزائر بقسنطينة

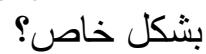

ويمكن الإجابة على هذا التساؤل المحوري من خلال محاولة الإجابة على الأسئلة

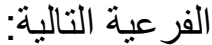

- - هل تتبنى مؤسسة بريد الجز ائر بقسنطينة التسويق الداخلي بكل مكوناته، أم أنها

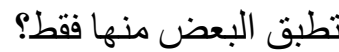
إن كانت المؤسسة تطبق التسويق الداخلي، هل تعتبر أن تحفيز الموظفين هو أهم مكون للتسويث الداخلي بالنسبة لهاب

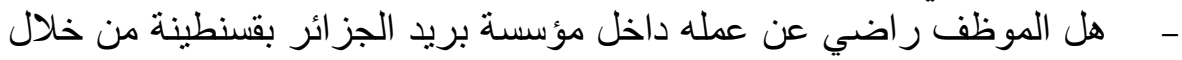
تطبيق برنامج التسويق الداخلّي؟ 2- 2 فرضيات الدراسة

في محاولة لمعالجة الإشكالية المطروحة والإجابة على التساؤلات الفرعية تمت

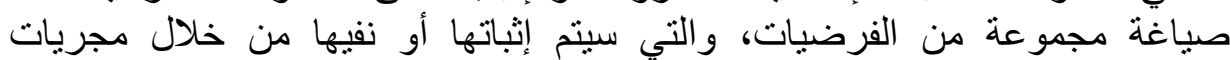

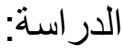
- - ت تتبنى مؤسسة بريد الجزائر التسويق الداخلي بكل مكوناته و إجر اءاته. 
- - يعتبر عنصر التحفيز، في مؤسسة بريد الجزائر، أهم عنصر من عناصر

التسويق الداخلي. - موظف أو بريد الجزائر بقسنطينة راضي عن عمله من خلال تطبيق سياسة التسويق الداخلي.

3 - أهداف الدراسة

تهدف هذه الدراسة للتعرف أكثر عن مدى تطبيق مؤسسة بريد الجزائر

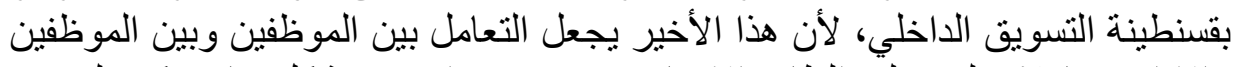

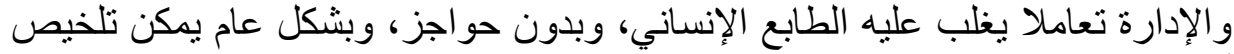
أهداف الدر اسة في النقاط التالية:

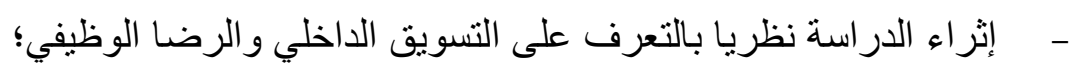
- - التعرف على أهمية تطبيق التسويق الداخلي بالمؤسسات الخدمية؛

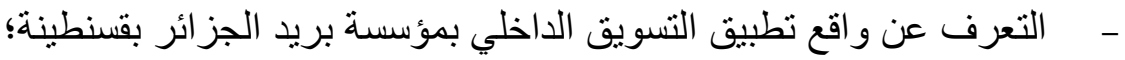

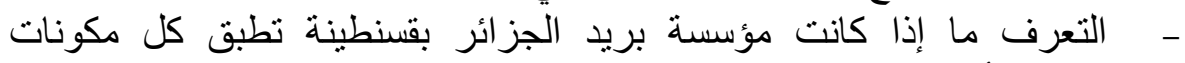

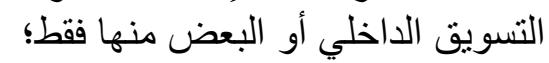
- - التعرف على ما إذا كان للتسويق الداخلي، بمؤسسة بريد الجزائر دورا في تحقيق الرضا الوظيفي. 4 - أهمية الدراسة

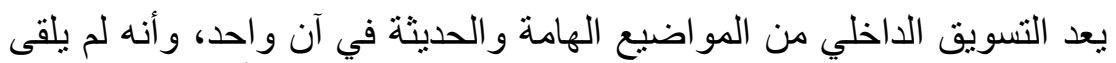

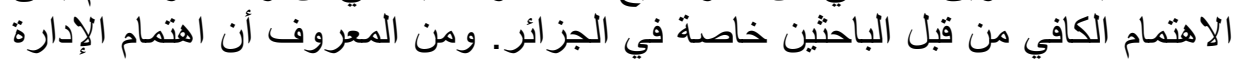

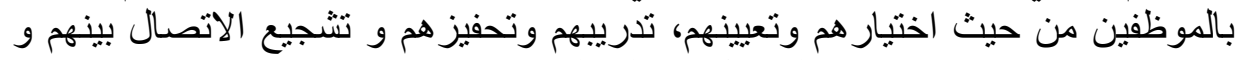

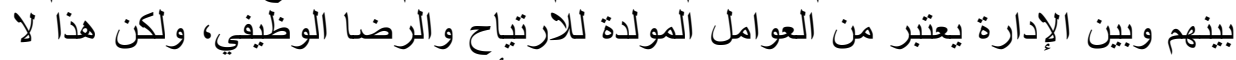

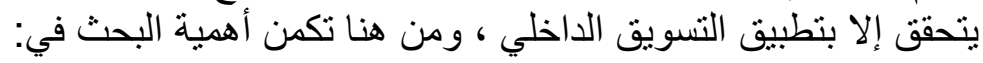

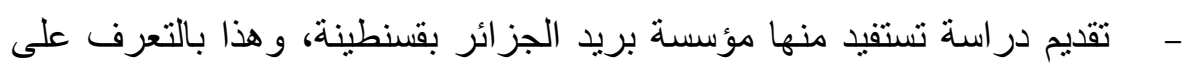
التسويق الداخلي؛ بر امجه بكل ثقة؛؛ تعرف المؤسسة عن التسويق الداخلي ومدى أهميته، بسمح لها بتبني

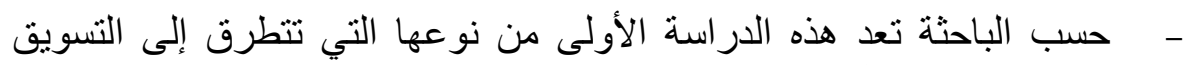

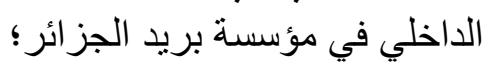

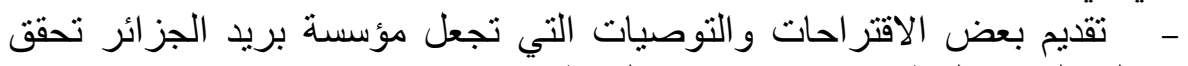
من خلالها الرضا الوظيفي، وزيادة كفاءة الموظفين. 5- منهجية الدراسة 
الأكيد أن نجاح أي عمل علمي يتوقف على مدى تناسب التقنيات العلمية والمنهجية المتبعة في جمع المعلومات المتعلقة بموضوع الدراسة. وفي هذه الدراسة سيعتمد

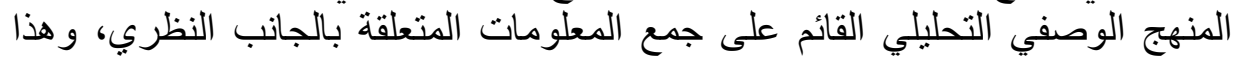
بالاعتماد على الكتب و المجلات و الرسائل الجامعية.

ولاستكمال الدراسة بجانبها العملي اعتمد منهج دراسة الحالة، وقد تم تصميم

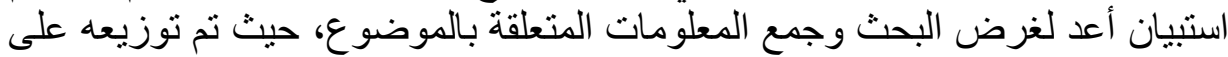

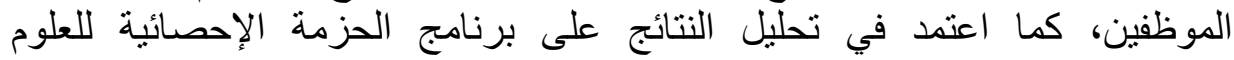
SPSS الاجتماعية،

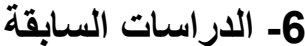

أ. دراسة صالح عمرو كرامة الجريري، أثر التسويق الداخلي وجودة الخدمات

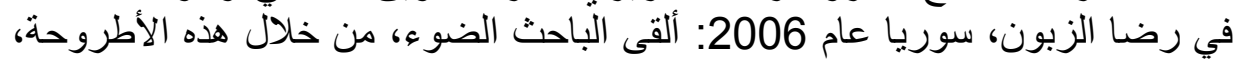

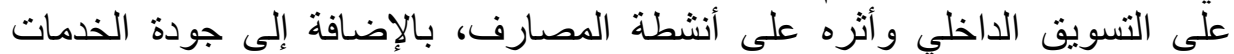
المصرفية ودور ها في رضا الزبون، وقد كانت الدراسة على واقع المصارة المصارف اليمنية حيث توصلت إلى: ت إنى - أن أن برامج التسويق الداخلي الفعالة تساهم بصورة إيجابية في نجاح

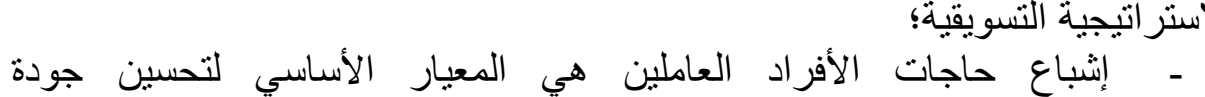

الخدمات، د... بـة سعيد شعبان حامد، أثر التسويق الداخلي كمدخل لإدارة الموارد البشرية

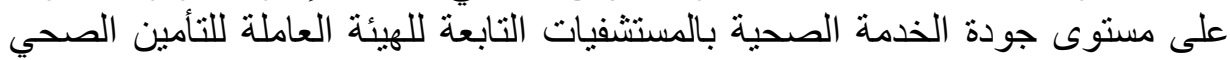
بالقاهرة، يناير 2011: حاولت هذه الدر اسة العمل على تحقيق عدة أهداف منها:

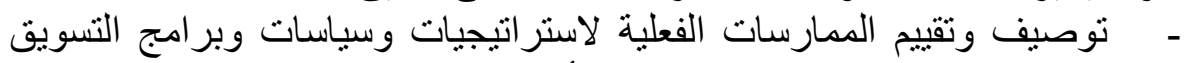

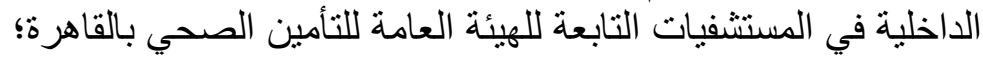

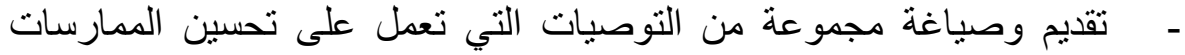

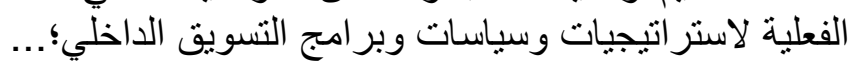

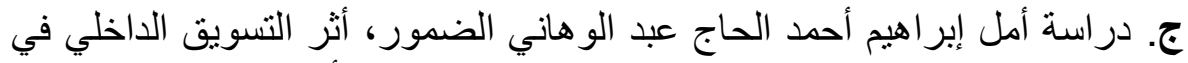

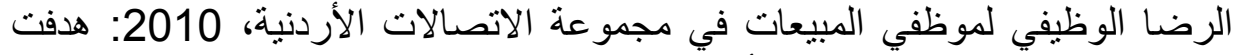

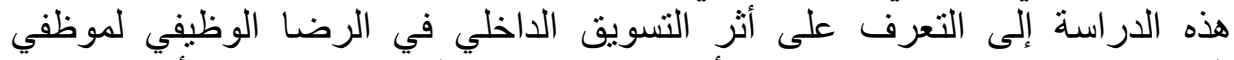

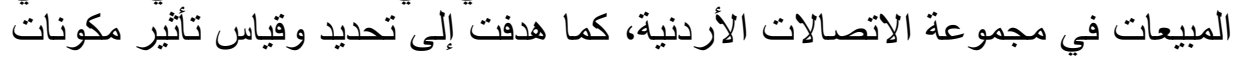

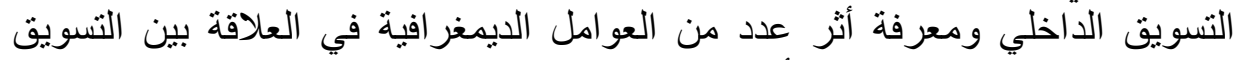

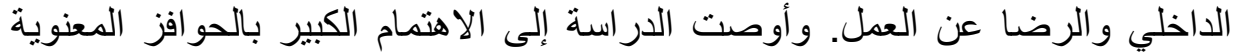

$$
\text { و المادية، وضرورة تطبيق التسويق الداخلي من منظور التسويق. }
$$

Amjad Abu Elsamen and Muhammad Alshurideh, The Impact of در اسة Internal Marketing on Internal Service Quality, A case Study in a Jordanian 
Pharmacetical Company,

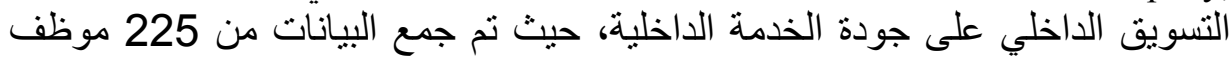

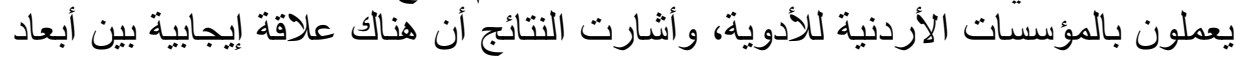

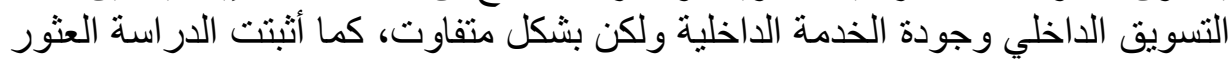

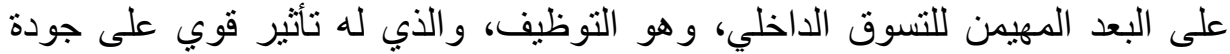

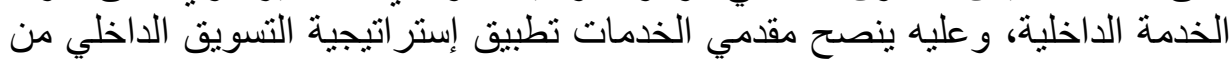

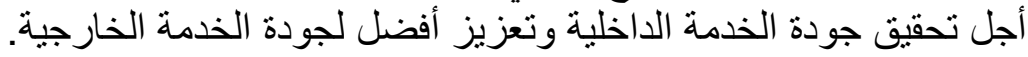

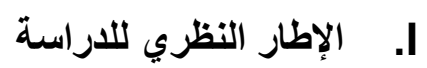

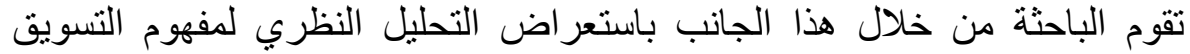

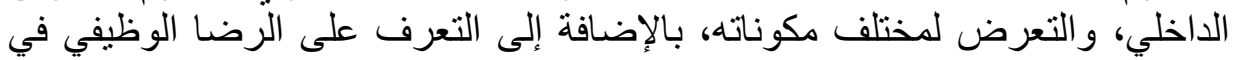

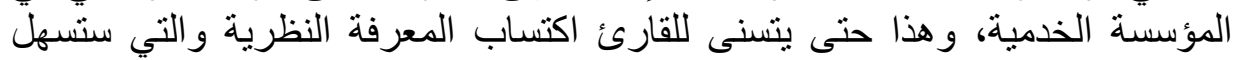

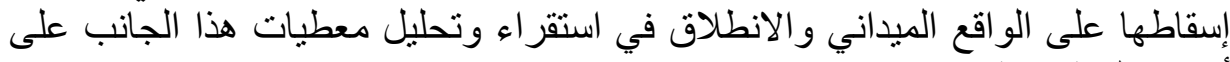
أسس علمية بحتة.

\section{أولا: التسويق الداخلي: المفهوم و المكونات}

يمارس الموظفين في المؤسسات الخدمية الجزء الأكبر والأهم من وظيفة التسونة التهويق،

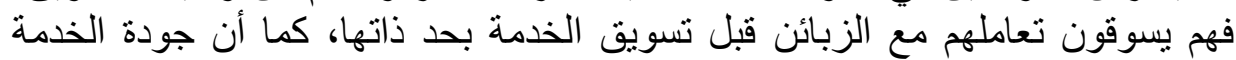

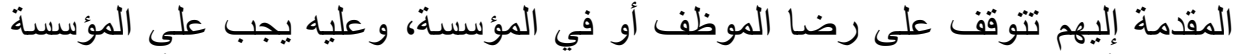

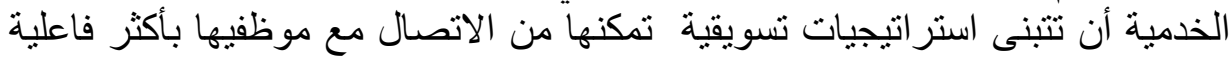

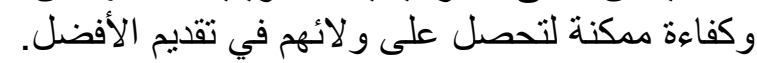

يعتمد التسويق الداخلي على استخدام المنظور التسويقي لإدارة الموظفين وتنمية

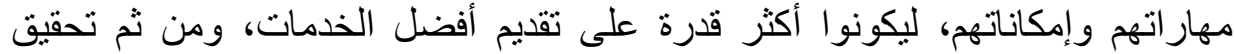

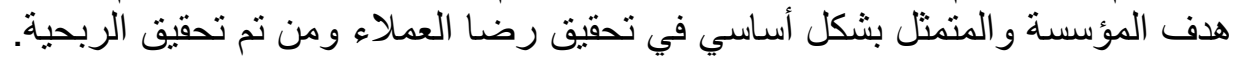

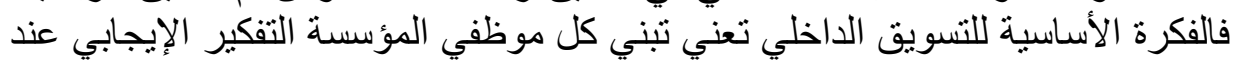

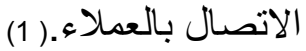

\section{- مفهوم التسويق الاخلي}

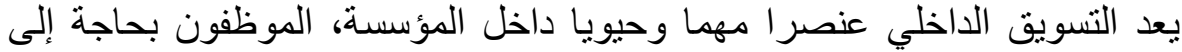

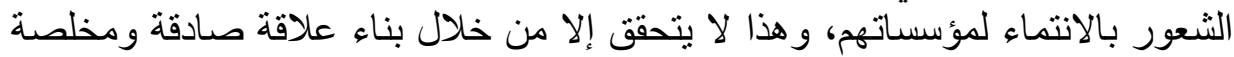

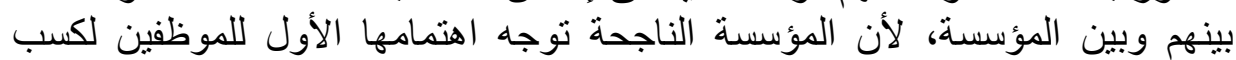
رضاهم لينتقل هذا الرضا مباشرة إلى العميل الخارجي لها. 
لقد ظهر التسويق الداخلي من أجل حل المشاكل التي تحدث بسبب عدم وجود جودة

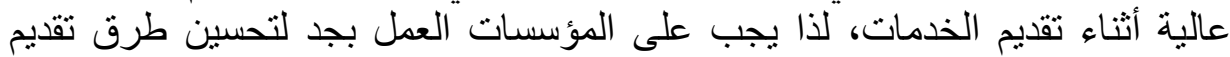

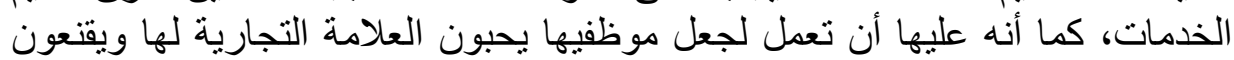

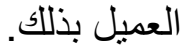

إن استراتيجيات التسويق الخارجي في المؤسسة لن تتحسن إلا عن طريق تحسين

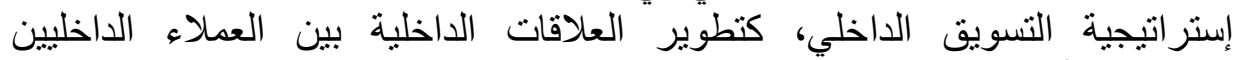

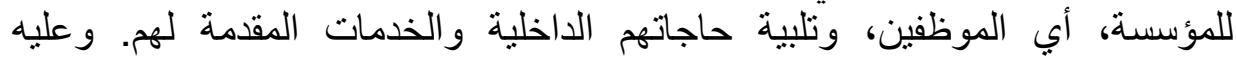
فالتسويق الداخلي هو " الجهد المبذول من طرف المؤسسة الخدمية من أجل توفير

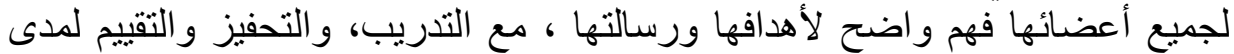
تحقيق الأهداف المرجوة." (2)

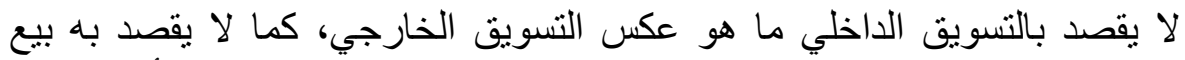

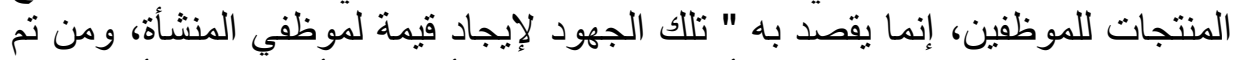

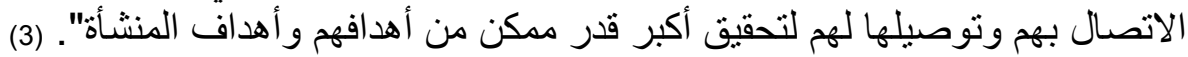
و عليه فالطرق التقليدية للتسويق الخارجي ذات فعالية محدودة عند تطبيقها في مجال

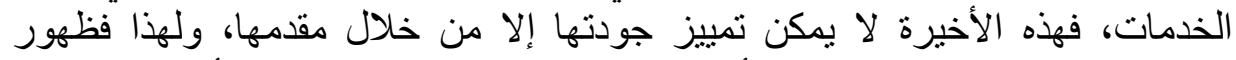

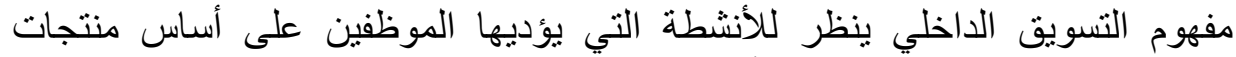

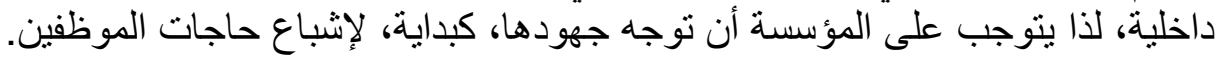

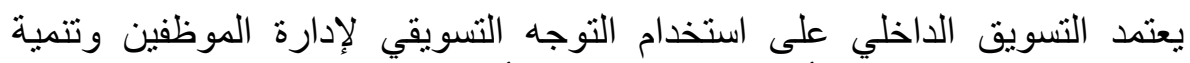

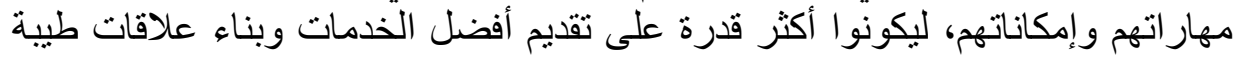

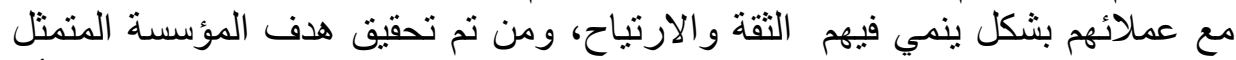

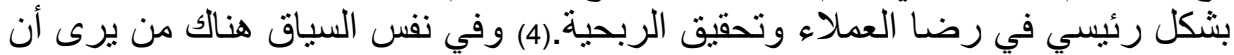

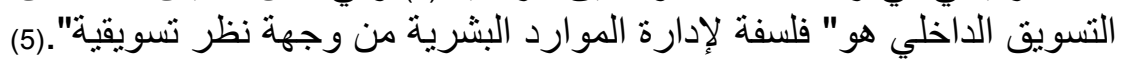

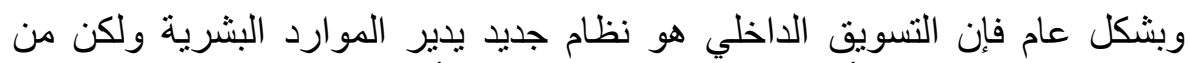

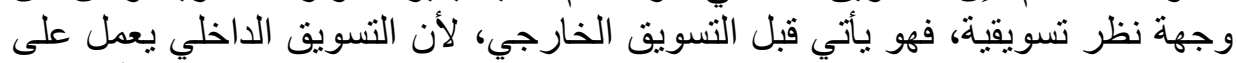

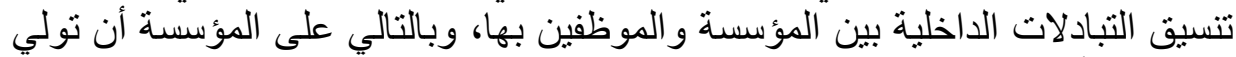

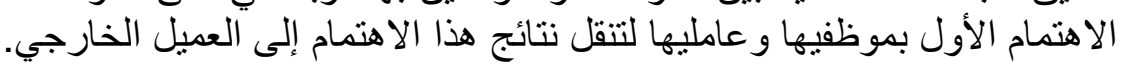

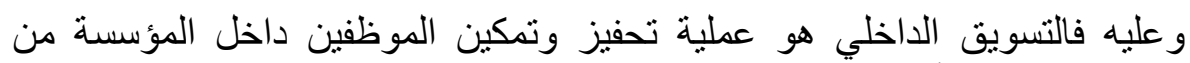

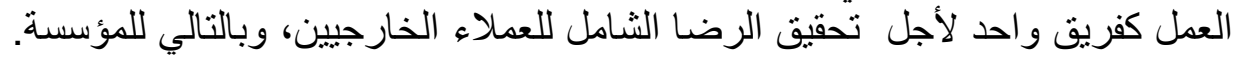

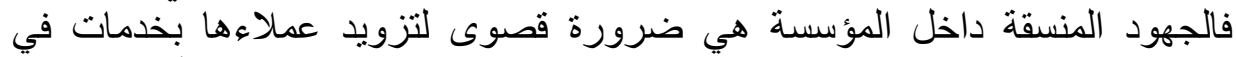

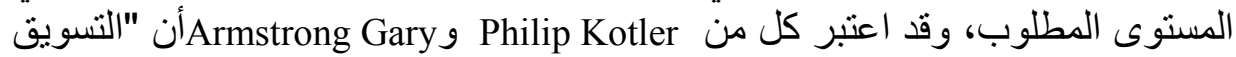

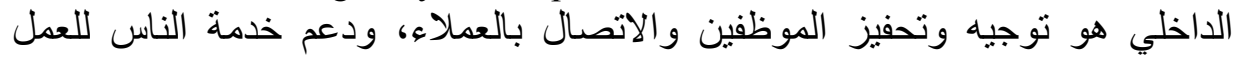
كفريق و احد لتقديم الأفضل للعملاء." (6) وناهن - مكونات التسويق الاخلي 
إن الهدف الرئيسي للتسويق الداخلي هو خلق قوة عمل مستقرة ومتطورة في

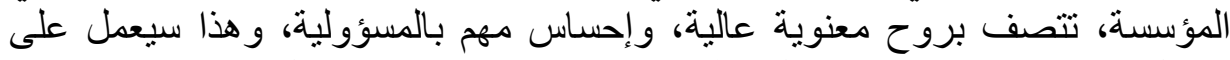

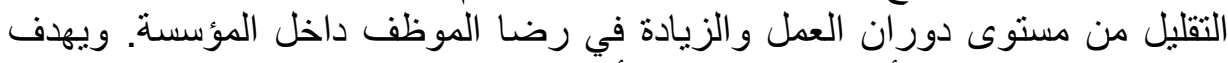

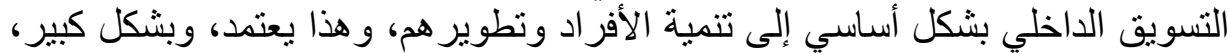
على التدريب المكثف و المتو اصل للموظفين في مختلف الفترات. يقوم التسويق الداخلي على مجموعة من المكونات، و وهي:

-

على كل مؤسسة خدمية التركيز على وضع سياسة محددة من أجل اختيار الموظفين

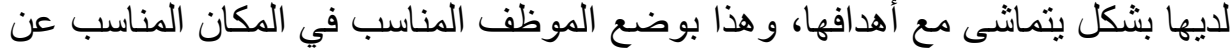
طريق الاختبار ات و المسابقات أو عن طريق أهن الترقية الداخلية.

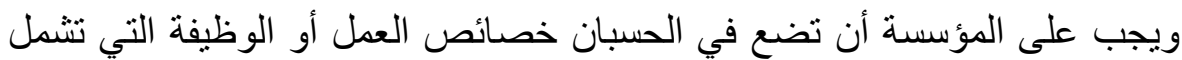

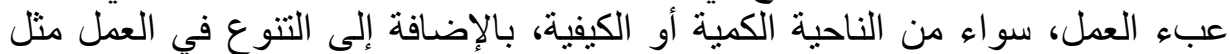

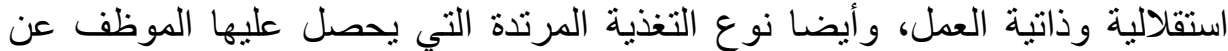
العمل المقدم، دون غض الته النظر عن ظروف النغ العمل المتوفرة من الناحية المادية،

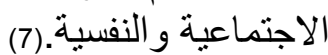

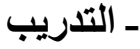

يعرف التدريب على أنه " ذلك النشاط المستمر لتزويد الفرد بالمهام والخبرات

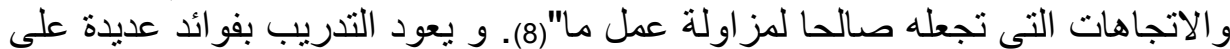

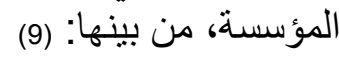

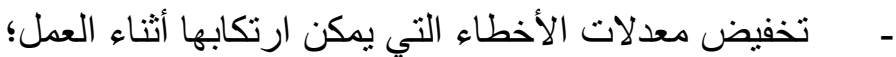

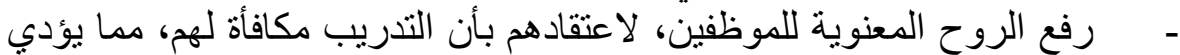

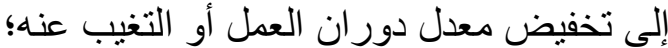

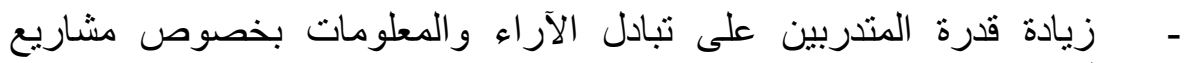

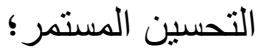
- - المساهمة في إشعار الموظف بالاستقرار الوظيفي. و عليه فإن تحديد الاحتياجات التدريبية وفق خطة مدروسة، وبدقة متتاهية، يؤدي حتما لزيادة فاعليته، و هذا بالمساهمة في رفع كفاءة الموظف عنف عند تنفيذ المشاريع وخدمة

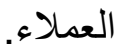

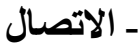

يعتبر الاتصال العنصر الملموس من عناصر التسويق الداخلي، حيث يستخدم في التي

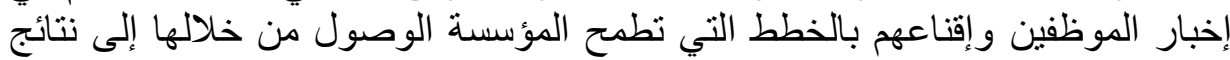

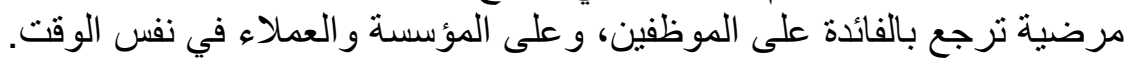


يعرف الاتصال الداخلي في المؤسسة على أنه "عملية تحويل المعلومات من فرد

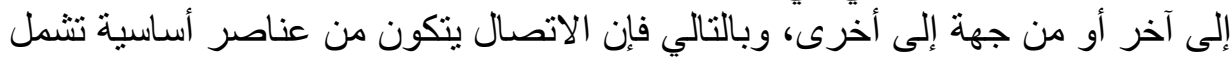

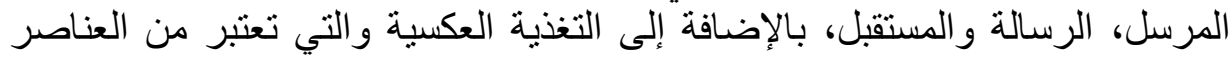
المهمة، كونها تساعدنا على تقييم الاتصال"(10).

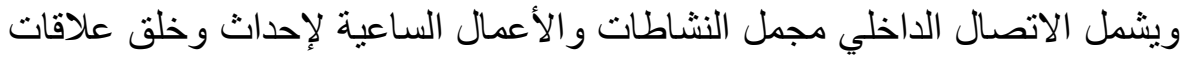

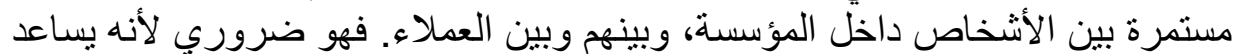

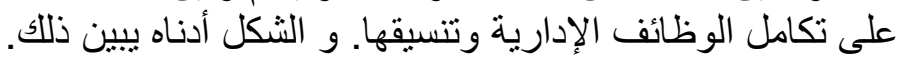

الثكل رقم 01: تكامل الوظائف الإدارية وتتسيقها من خلال الاتصال

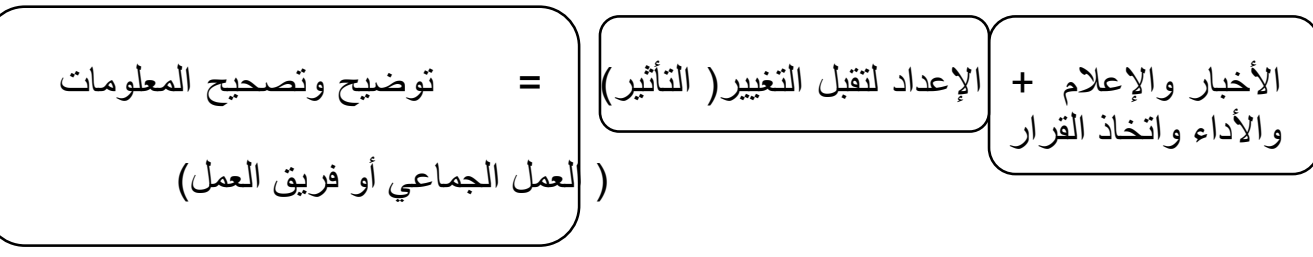

المصدر: عبد الغفار حنبفد، محمد فريد الصحن، إدارة الأعمال، الدار الجامعية، بيروت،

1991، ص: 386.

والاتصال هو عبارة عن سلسلة من المعلومات التي تنقل من المرسل إلى المرسل المبل

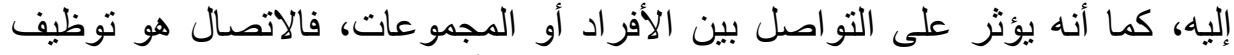

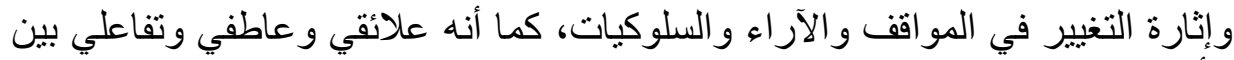
الأفر اد. (11) الثارة

\section{- تفويض الصلاحيات والإقرار بجهود العاملين}

تعتبر عملية تفويض الصلاحيات للموظفين عاملا مهما في إنتاج وتقديم أفضل

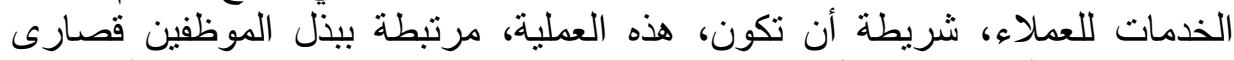

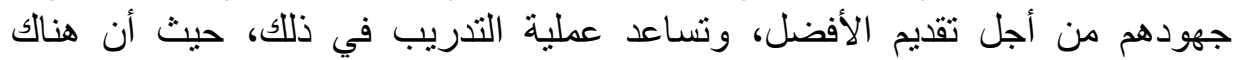
افتراضا منطقيا وارتباط قويا بين تطوير وتدريب الموظفين وتزويدهم بالمسؤوليات الضرورية لإنجاز أعمالهم.(12)

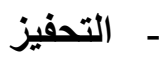

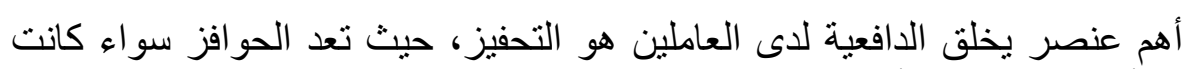

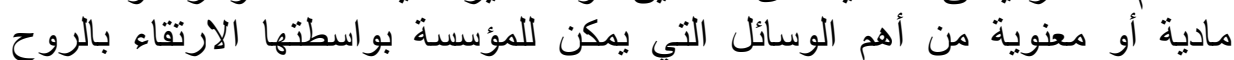

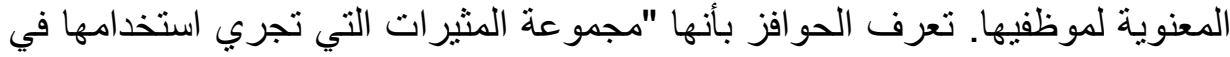


إثارة الدافعية للفرد، حيث أنها مؤثرات خارجية من شأنها أن تحرك السلوك الذاتي

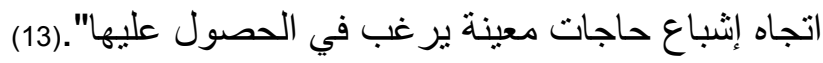

ثانيا: الرضا الوظيفي

من بين ما تطمح إليه المؤسسة هو تحقيق الرضا الوظيفي، فهذا الأخير إن توفر

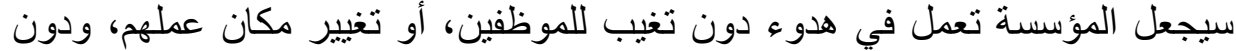

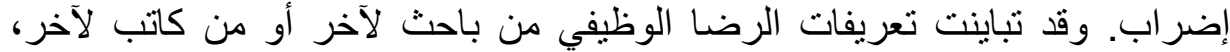

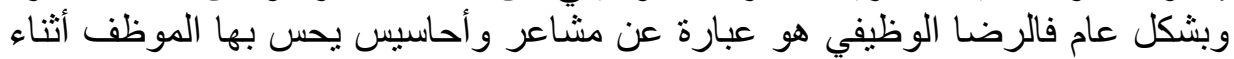
تأدية وظيفته.

لقد عرفFrouz الرضا الوظيفي على أنه "شعور الثخص نحو وظيفته أو عمله، فالشعور الإيجابي يتبعه الرضا الوظيفي، بينما الثعور السلبي التئي التبعه عدم الرضا الوظيفي".(14)ويتضمن الرضا الوظيفي عدد من الأبعاد تتمثل في:(15) - - ارتباط مباشر بين الرضا الوظيفي للفرد و قدراته وميوله وقيمه وسماته

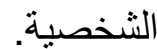
- - الرضا الوظيفي ما هو إلا انعكاس لمشاعر الفرد، الايجابية أو السلبية، اتجاه المتغير ات المادية و المعنوية المرتبطة لونة بالوظيفة.

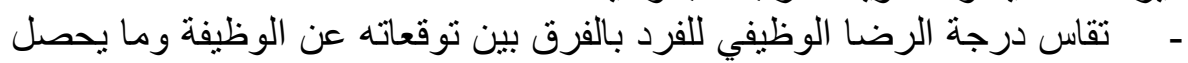

يجب على المؤسسة أن توفر لموظفيها جو من الاحتر ام و التقدير، فالأساليب القديمة

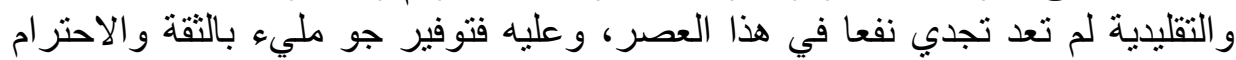

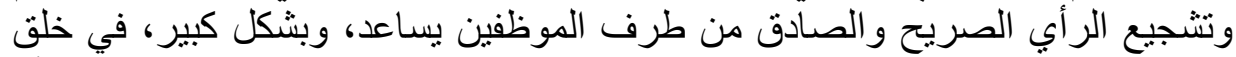
محيط مليء بالرضا وحب العمل، كما يخفف من تذمر و استياء الموظفين وتغيبهم، أو تغيير المؤسسة.

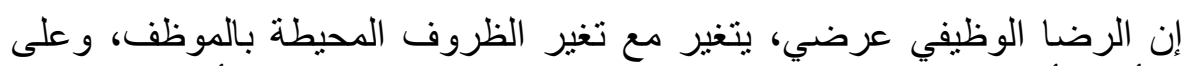

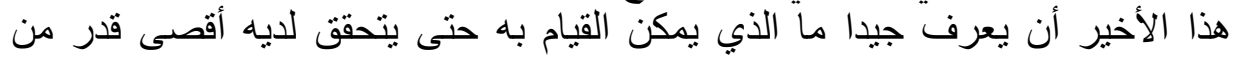

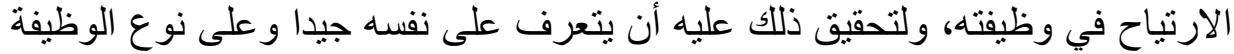

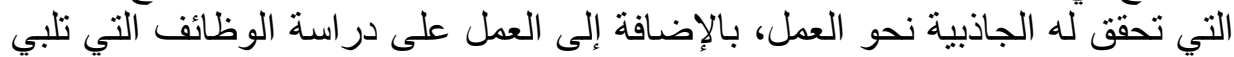

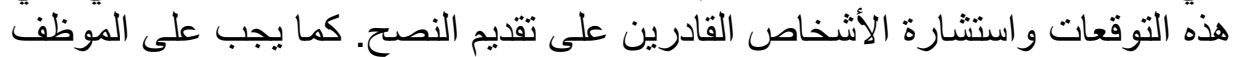

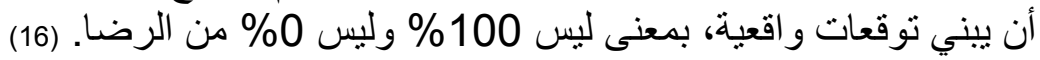

\section{ـ الآثار الإيجابية للرضا الوظيفي}

تستطيع المؤسسة أن تتعرف على درجة رضا الموظف أو درجة تحقق الرضا

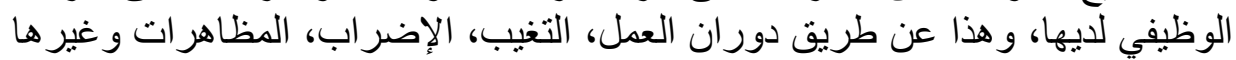

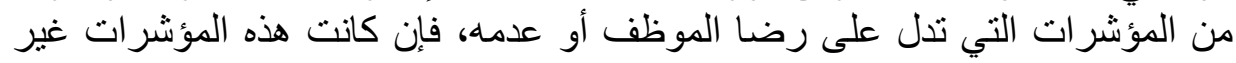


موجودة في المؤسسة فهذا يعني تحقق الرضا الوظيفي.ومن الآثار الإيجابية للرضا

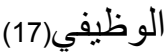

- - مقيق المؤسسة لأهدافها؛ - يكون الموظف أكثر إيجابية في التعامل مع المشكلات التي تواجهه و الخاصة

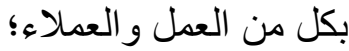

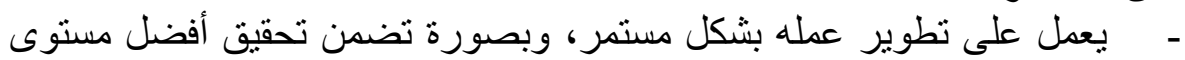

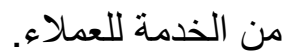

\section{ـ الآثار السلبية لانعدام رضا الوظيفي}

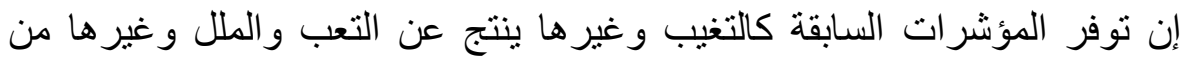

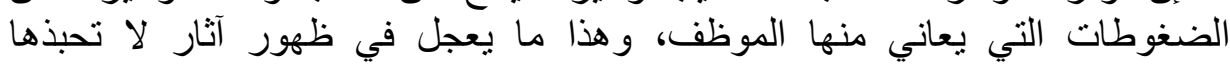
المؤسسة وبالتالي ينتقل الموظف إلى عدم الرضا عن الوظيفة، من بين هته الآثار : (18)

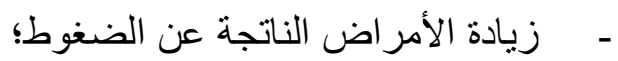

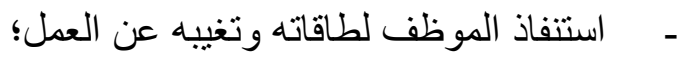

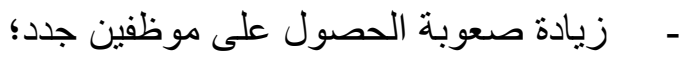
- وجود نظرة سلبية عامة اتجاه المؤسسة؛

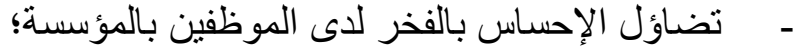

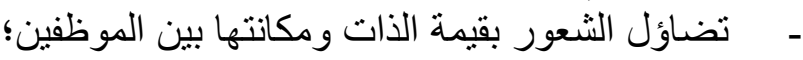

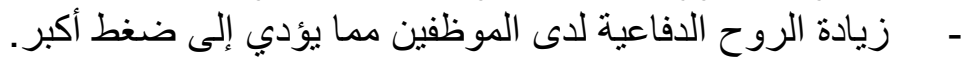

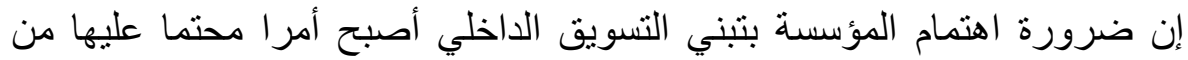

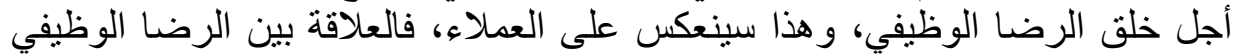

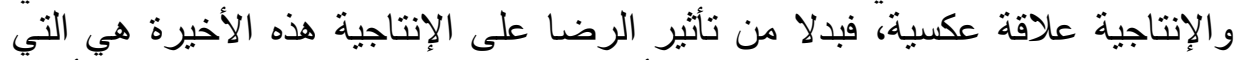

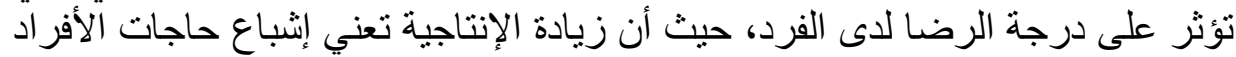

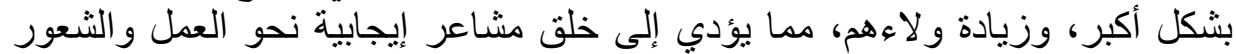
بالرضا.

وقد أظهر الباحثان محمد أحمد سليمان وسوسن عبد الفتاح وهب أن هناك الأك علاقة بين

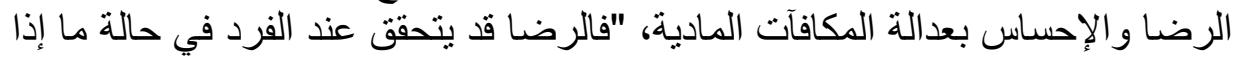

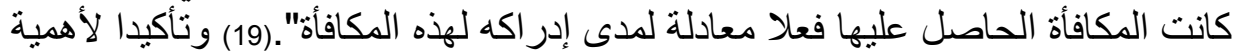

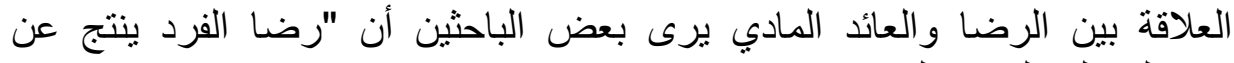

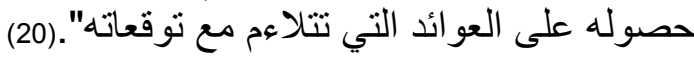

لاستكمال الدراسة بجانبها العملي اعتمدت الباحثة الإسة على استبيان أعدته لغرض هذه الإنه

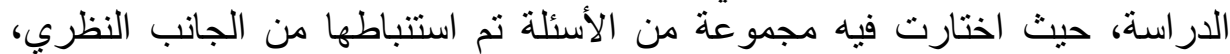




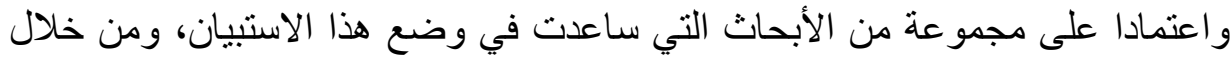

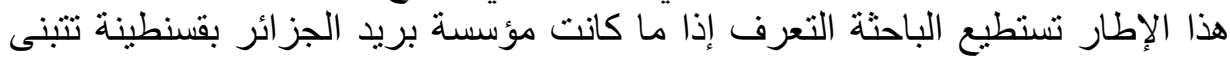

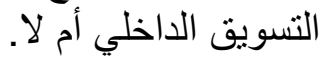

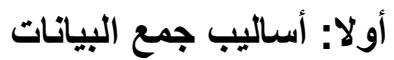

اعتمدت الباحثة عند استعراضها للجانب النظري على الكتب والمقالات العلمية المتخصصة بموضوع الدر اسة، و هذا من خلال توظيف المنهان المنه الوصفي.

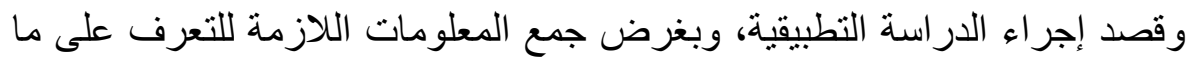

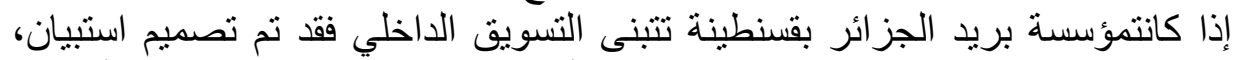

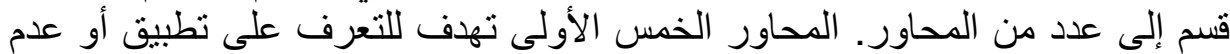

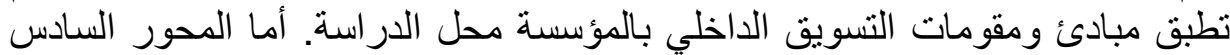

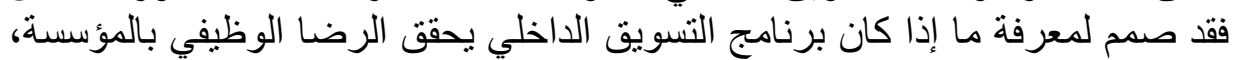

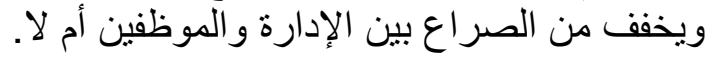

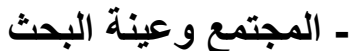

يصل عدد موظفي قطاع البريد بولاية قسنطينة إلى 745 موظفا، وقد اعتمدت

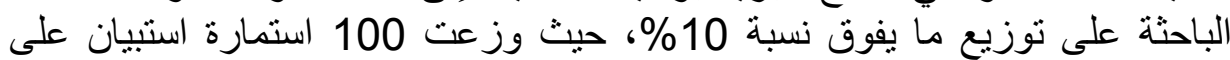

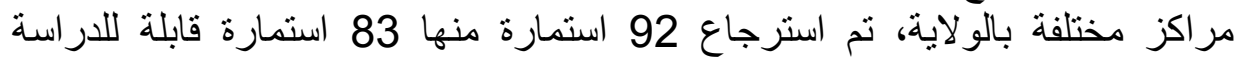
وبالتالي فقد خصصت الباحثة ما نسبته 83\% للاعة اسة.

تتشكل هذه الاستمارة من جز أين هما:

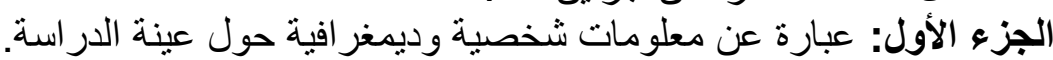

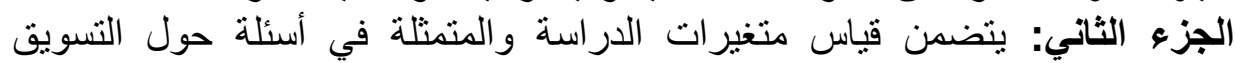

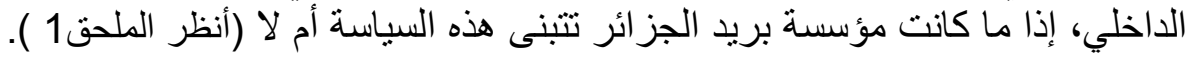

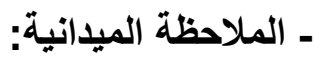

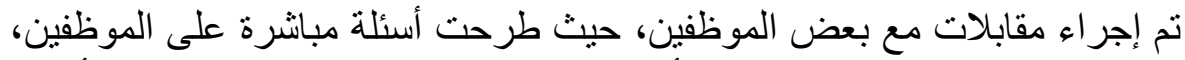

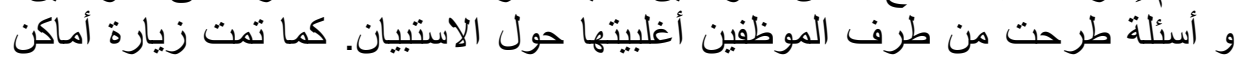
العمل من أجل الوقوف على واقع تعامل الموظفين مع بعضهم البعض وتعامل الإدارة

ثانيا: اختبار الصدق والثبات

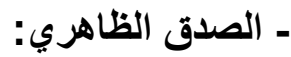

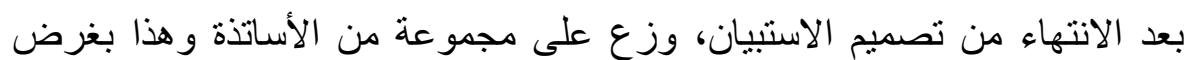

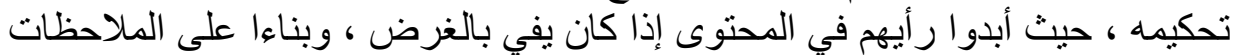

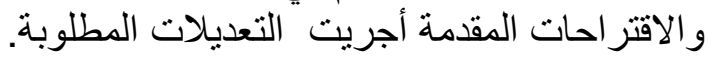


تم استخدام اختبار ألفا كرونباخ Cronbach Alpha من أجل معرفة ثبات أداة القياس

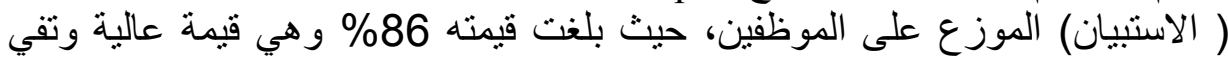

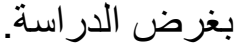

\section{تالثا: تحليل النتائج}

فيما يلي عرض لنتائج أسئلة الدراسة التي جاءت في الاستبيان،وهذا فيما يخص

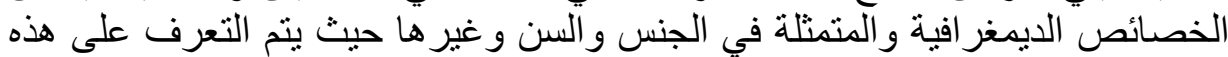

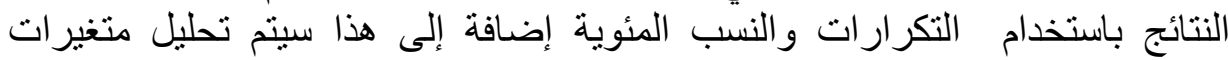
التسويق الداخلي من خلال الوسط الحسابي و الانحر اف المعياري.

\section{ـ تحليل عينة الدراسة:}

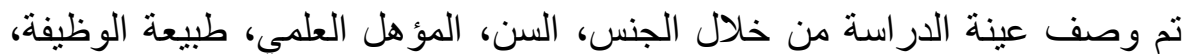

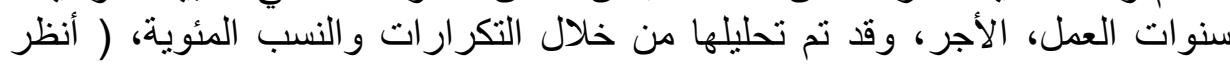

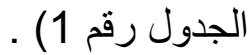

يلاحظ من الجدول رقم 1 أن نسب أفراد عينة الدراسة منقاربة بين الجنسين، ولكن

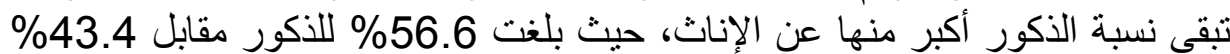

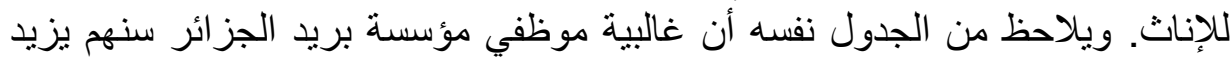

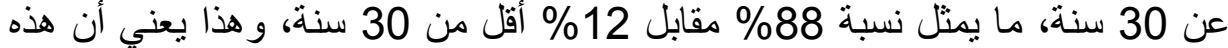
المؤسسة تشغل الموظفين الذين يملكون خبرة.

أما عن المؤهل العلمي، فأعلى نسبة توصلت إليها النتائج هم الموظفين ذوي

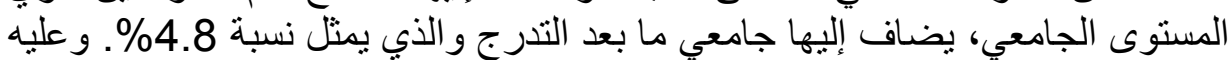

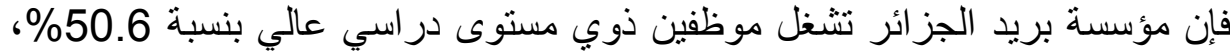

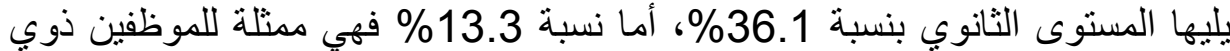

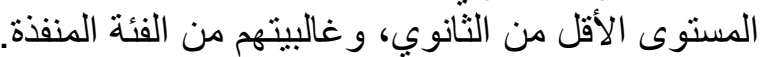

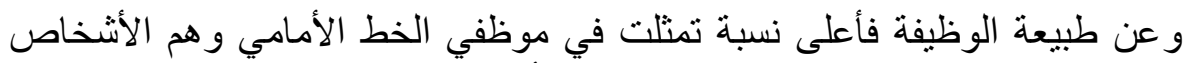

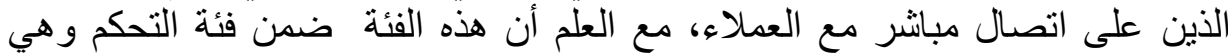

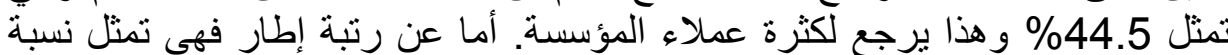

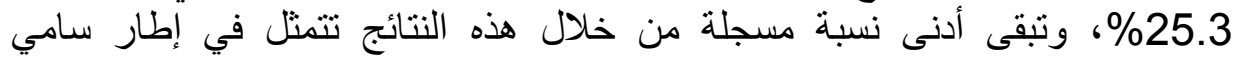

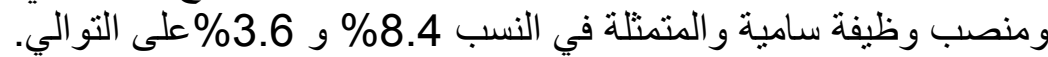

وبالنسبة لسنوات العمل ومن خلال الجدول رقم 01 دائما يلاحظ بأن أعلى نسبة

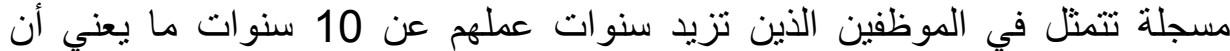

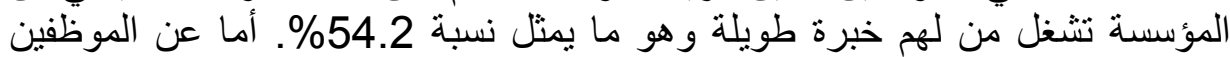


الذين يعملون بين 5 إلى 10 سنوات فيمثلون نسبة 36.1\% و وتبقى أقل نسبة مسجلة هم الموظفين الذين عدد سنو ات عملهم تقل عن 5 سنو ات و هذا بنسبة 9.6. 9.

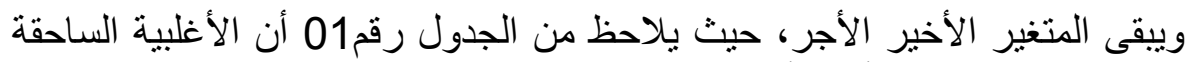

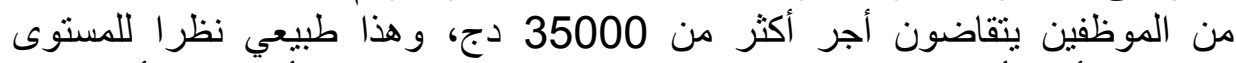

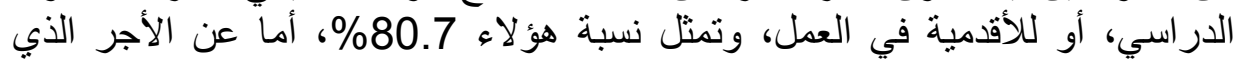

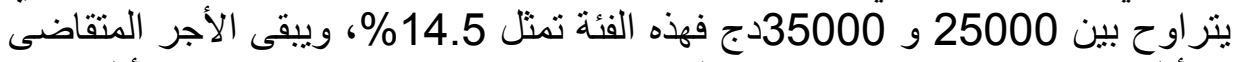
والأقل من 18000دج بالإضافة إلى ما يزيد عنه حنى 25000دج الأقل نسبة

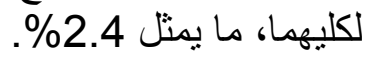

\section{رابعا: عرض آراء العينة حول متغيرات التسويق الداخلي}

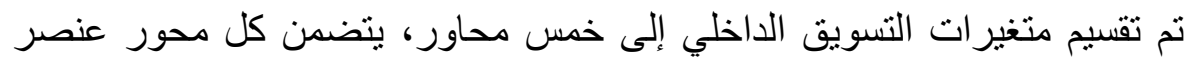

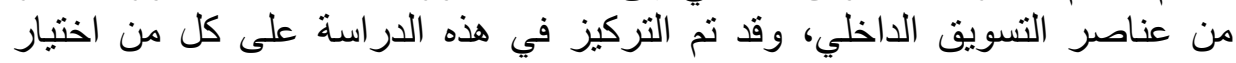

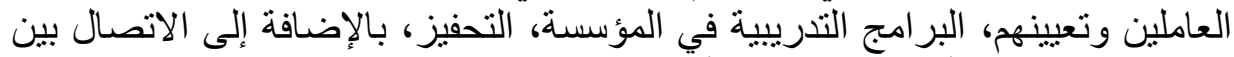

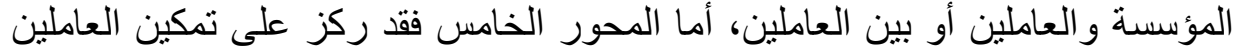

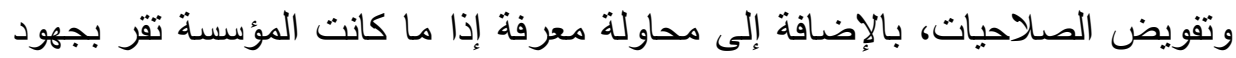

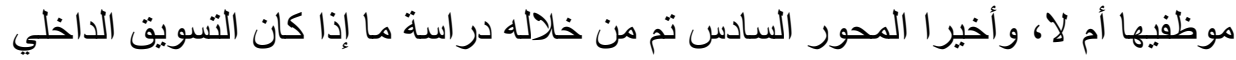

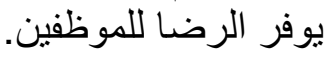

العتمدت الباحثة على سلم ليكرت الخماسيفي توزيع الإجابات، وكانت المستويات من

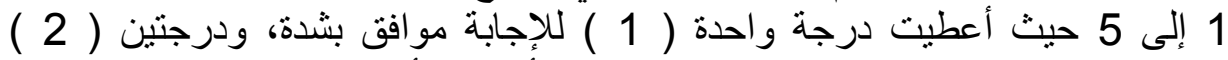

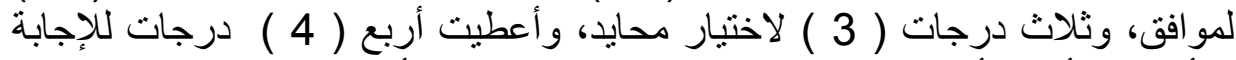

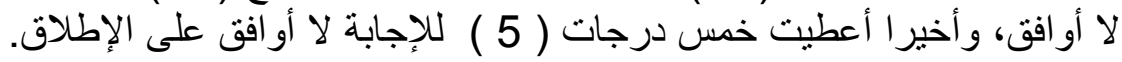

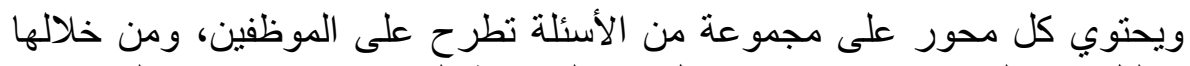

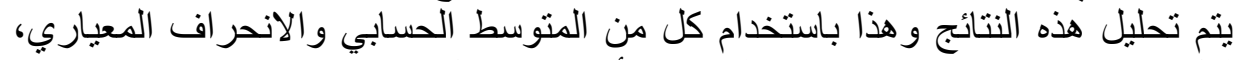

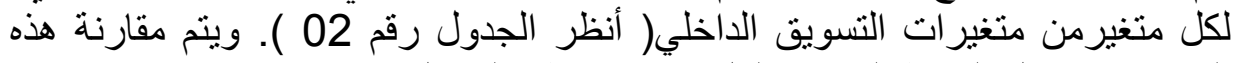
النتائج من خلال الوسط الحسابي لكل محور النظ النظر الجدول رقم 03 ) ). و و عليه يتم التعليق على نتيجة حساب المتوسط الحسابي حسب الفئات التالية:

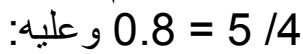

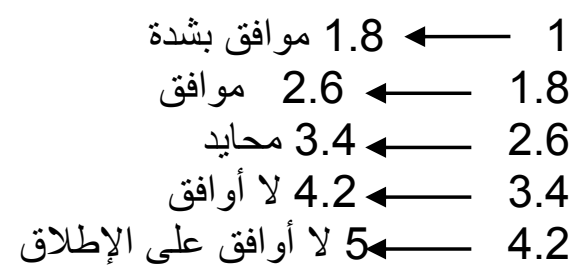


- الفرضية الأولى: تتبنى مؤسسة بريد الجزائر بقسنطينة التسويق الداخلي بكل

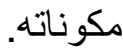

من هنا يمكن اختبار كل محور على حدا وهذا من المحور الأول حتى المحور الخامس، حيث أن كل محور يتضمن مجمو عة من الفقرات كالتهالي:

$$
\text { المحور الأول: اختيار العاملين وتعيينهم }
$$

يضم هذا المحور الفقرات 1، 2، 3، حيث كان الوسط الحسابي لهذا المحور تقدر

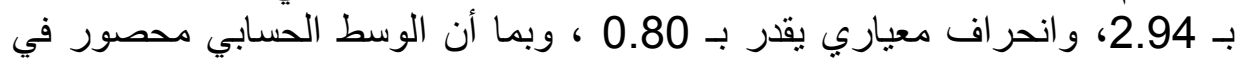

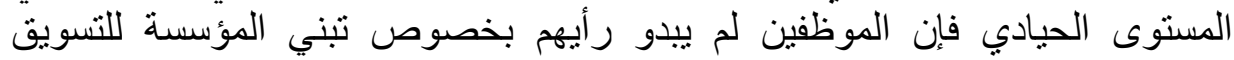
الداخلي من خلال اختيار العاملين وتعيينهر.

المحور الثاني: مدى توفر البرامج التدريبية

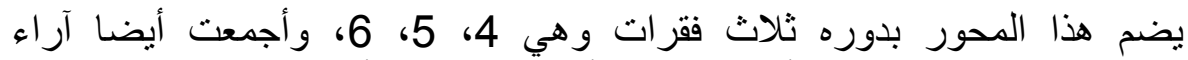

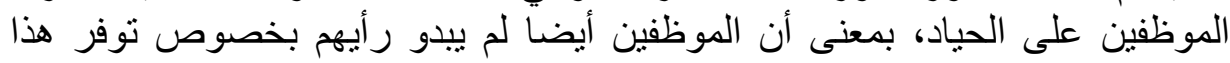

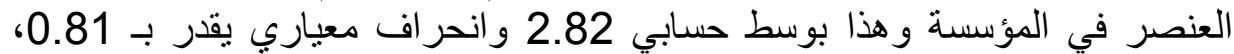
حيث أن الوسط الحسابي أيضا محصور ضمن المستوى الحيادي. المحور الثالث: توفر الحوافز والمكافآت

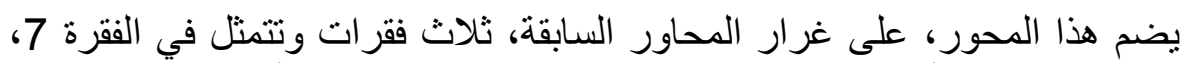

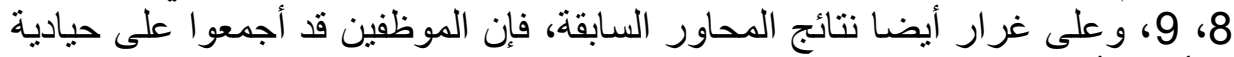

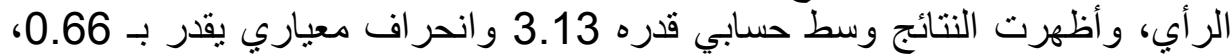
حيث أن الوسط الحسابي محصور ضمن مستوى الر أي الحيادي.

المحور الرابع: الاتصال ونقل المعلومات

يضم هذا المحور خمس فقرات وتمتد من الفقرة 10 حتى الفقرة 14، وهذا المحور

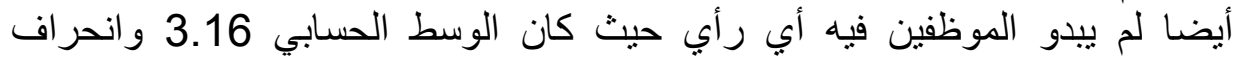
معياري 0.64، و النتيجة محصورة ضئ ضنمن المستوى الحيادي.

المحور الخامس: تفويض الصلاحيات والإقرار بجهود العاملين

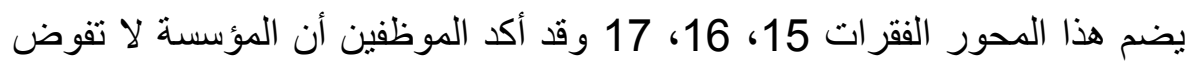
الصلاحيات لهم كما أنها لا تقر بجهودهم، حيث بلغت لنتائج مخرجات

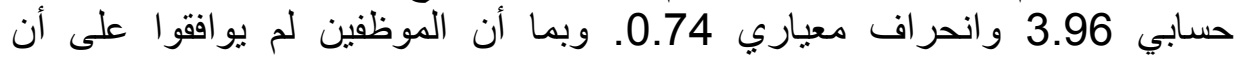

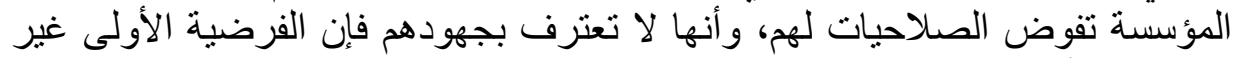
صحيحة. وأن المؤسسة لا تتبنى التسويق الداخلي بكل مكوناتها لأنئ. 
- الفرضية الثانية: يعتبر عنصر التحفيز في مؤسسة بريد الجزائر أهم عنصر

من عناصر التسويق الاخلي.

يوضح المحور الثالث برنامج الحوافز والمكافآت في المؤسسة، وكما ذكر آنفا فإن إن إنان

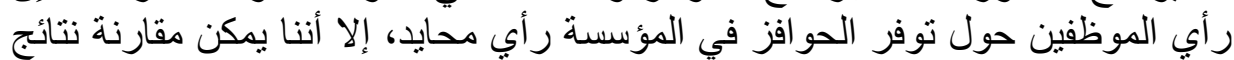
مدى توفر الحوافز في المؤسسة مع العناصر الأخرى الخون للتسويق الداخلي.

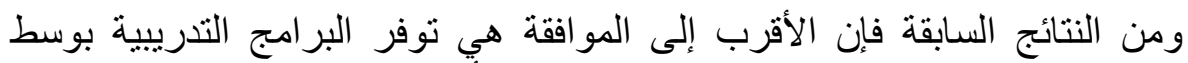

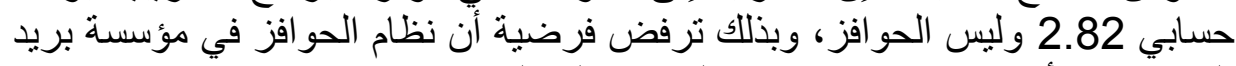

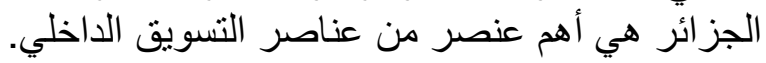

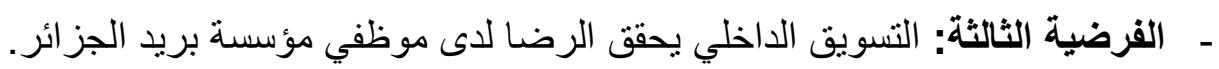
يتضمن المحور السادس الرضا الوظيفي من خلال برامج التسويق الداخلي، وقد

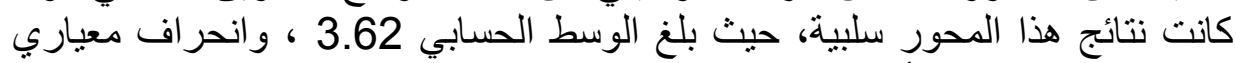

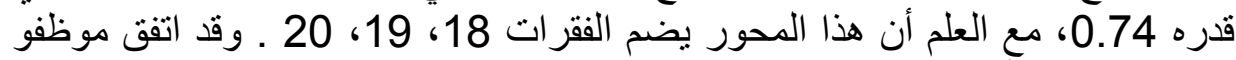

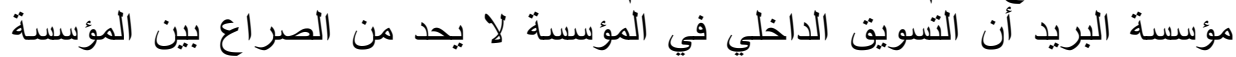

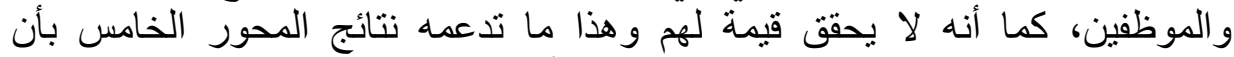

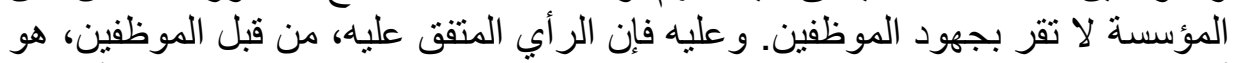

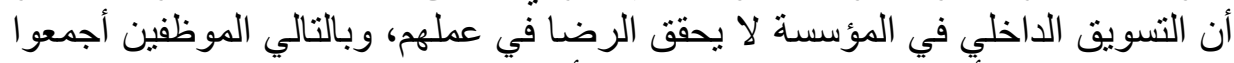

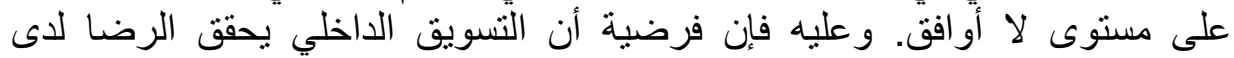

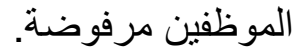

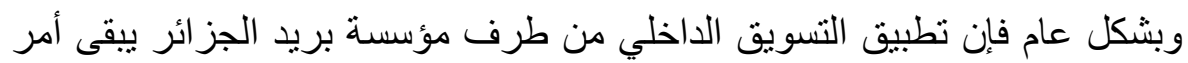

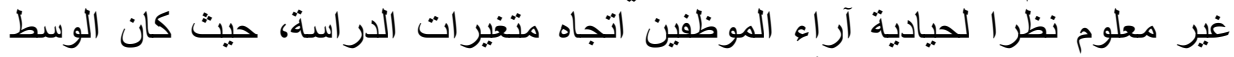
الحسابي للمحاور الخمس الأولى 3.20 و انحر اف معياري

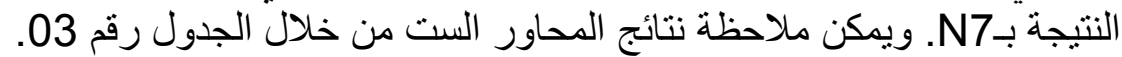

حيث: إلى غاية N1 الداخلي(انظر الجدول رقم 03) بحيث: N2 N4 N5 -

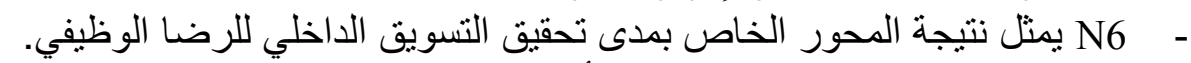
N7 - يمثل نتائج المحاور الخمس الأولى، حيث توضح نتيجة نطبيق التسويق الداخلي في المؤسسة بشكل عام. 


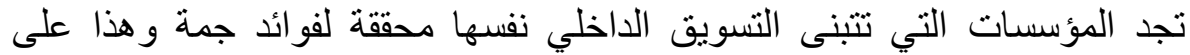

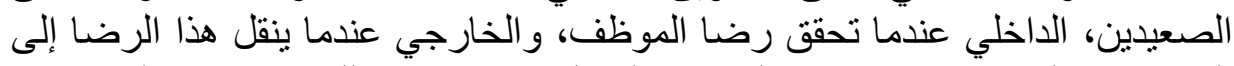

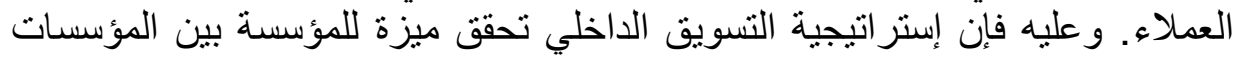

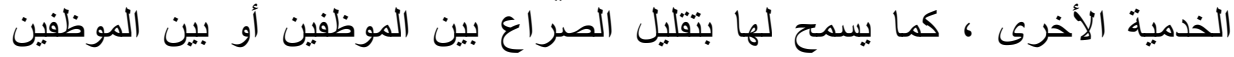

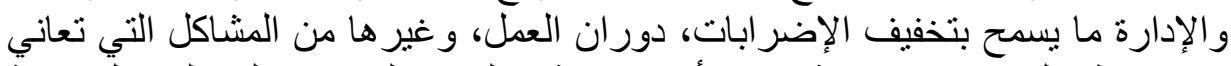

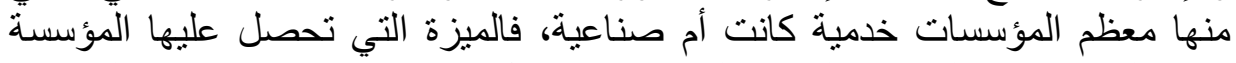

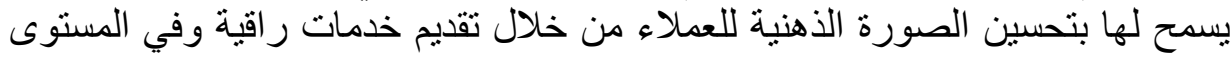
المطلوب.

و على العموم يمكن استخلاص أهم النتائج التي توصلت إليها الدر اسة في ما يلي:

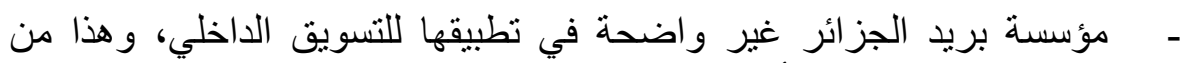

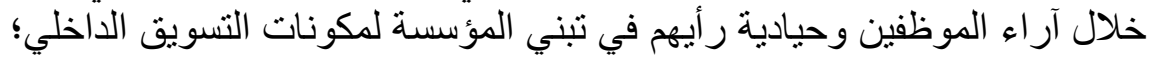

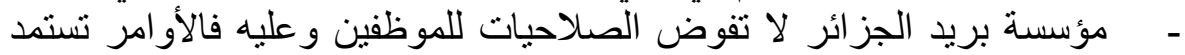

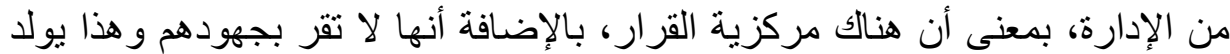

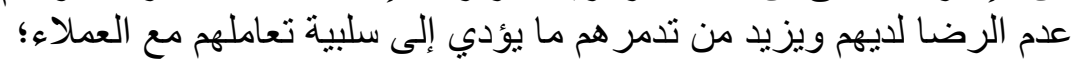

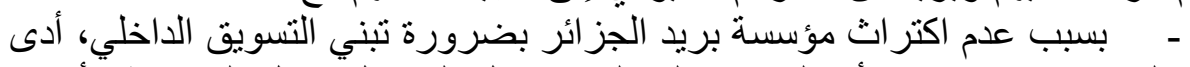
هذا إلى تصريح واضح بأن التسويق الداخلي لا يحل المشاكل داخل المؤسسة وأنه لا لان

يحد من الصر اع بداخلها.

و على ضوء النتائج السابقة يمكن تقديم مجمو عة من التوصيات و التي تتمثل في:

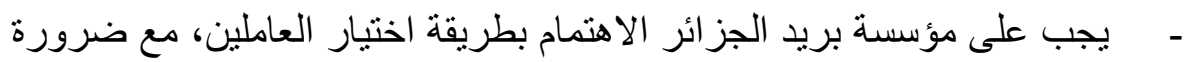

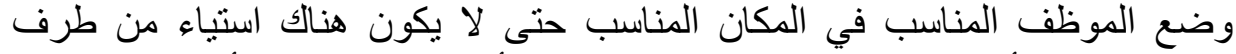

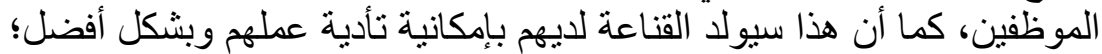

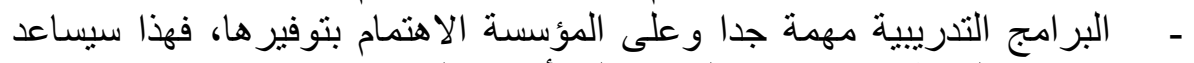

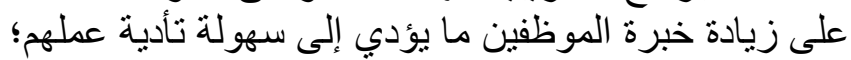

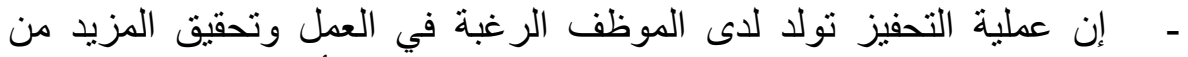
الجودة، و عليه على المؤسسة الاهتمام بهذا العنصر للها لله من أهمية كبيرة في تحقيق الهيق

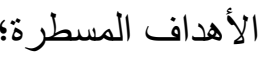

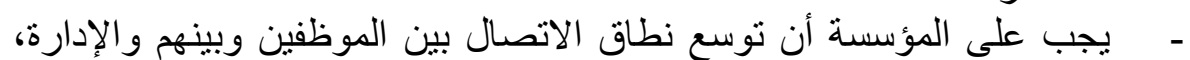

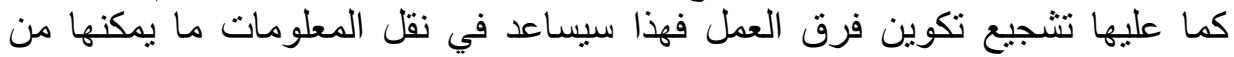

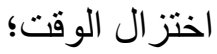

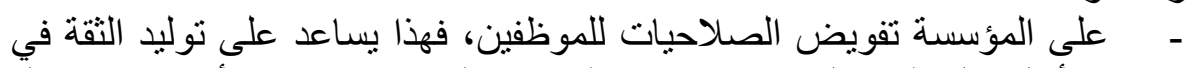
أنفسهم من أجل حل المشاكل مباشرة دون الرجوع الهرو إلى الإدارة، كما أن هذا سيحول دون التفكير من طرف الموظف في تغيير منصب عمله أو تغيير المؤسسة بحد ذالتهات ذاتها. 
1. صلالح عمرو كرامة الجريري، أثر التسويق الداخلي وجودة الخدمات في رضا الزبون،

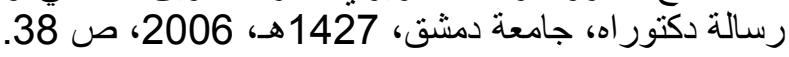
2 . Amjad Abu ELSamen and Muhammad Alshurideh, Impact of Marketing on Internal service Quality, International Journal of Business and Management, Vol 7, No 19 , 2012, pp 84- 85.

3 ـ أسامة أحمد، التسويق الداخلي، مجلة الأحساء، العدد 25، دمشق، ديسمبر 2008، على

marketing. Blogspot.com/ 2009/ 01/ internal marketing. Html. Osama 4 . Lewis Robert, Hospitality Marketing, the internal Approaches, comal hotel and Restaurant, quarterly, vol 30,No ( 3 ), 1989, P : 43.

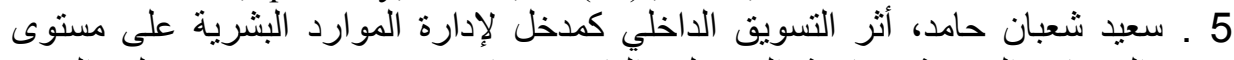

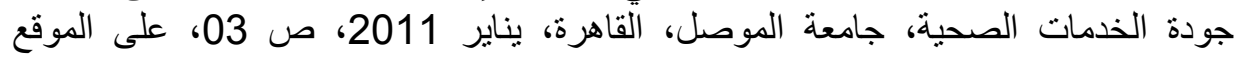
faculty. Ksu.edu.sa 6. Shiful Alam, The Marketing concepts, January 20, 2013,P : 01, Look, تاريخ السحب يوم 01/ 7 ـ عبد الباري ذرة، زهير نعيم الصباغ، إدارة الموارد البشرية في القرن، القرن الحادي والعشرين،

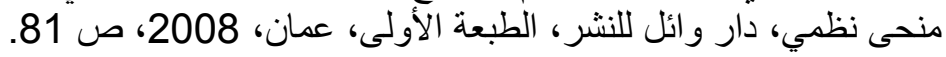

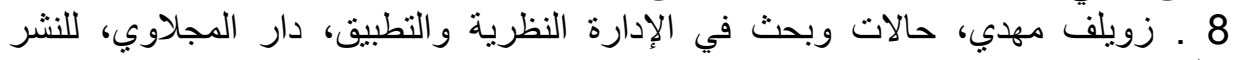

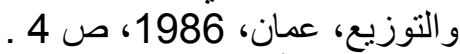
9 ـ محفوظ أحمد جودة، إدارة الجودة الثاملة، مفاهيم وتطبيقات، دار و ائل للنشر والتوزيع،

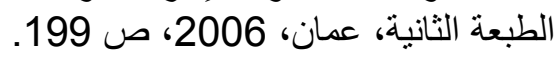
10 ـ إبري ولسون، اتجاهات جديدة في السوق، الدار الدولية للنشر ، مصر، 1996، ص61. 11 . Frédérique Alexandre Bailly et autres, Comportements humains et management, 4eme édition, Pearson, Paris, 2013, P : 110

12. Rafiq, M. Ahmed $\mathrm{P} K$, the scope of internal marketing defining the boundary between marketing and human resource management, Journal of marketing management, vol, 9, No 3, 1993, p 220.

13 ـ لوكيا الهاثمي، السلوك التنظيمي، دار الهدى للطباعة والنشر و التوزيع، الجزء الثاني، 14 ـ سالم تيسير الثرايدة، الرضا الوظيفي، أطر نظرية وتطبيقات علمية، دار الصفاء،

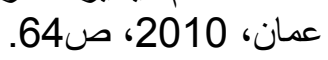
15 ـ منى شفيق، التسويق بالعلاقات، المنظمة العربية للتنمية الإدارية، القاهرة، 2005، ص

16 . Rene Davis, Job satisfaction, http : // www. career key. Org/ choose- acareer/ job- satisfaction. Ht, 2011.

$$
17 \text { ـ منى شفيق، مرجع سبق ذكره، ص ص 41-40. }
$$


18 ـ كامل بربر ، إدارة الموارد البشرية واكتفاء الأداء التنظيمي، المؤسسة الجامعية للار اسات

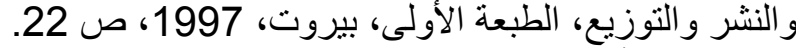

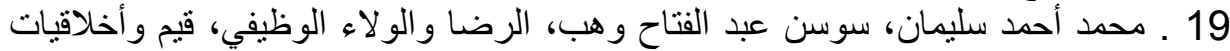

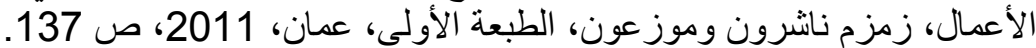

20 ـ المرجع السابق، صن ن ون 137.

جدول رقم (1): توزيع عينة الدراسة

\begin{tabular}{|c|c|c|c|}
\hline النسبة\%\% & التكرارات & فير & \\
\hline 56.6 & 47 & ذكر & \multirow{3}{*}{ الجنس } \\
\hline 43.4 & 36 & أنثى & \\
\hline 100 & 83 & المجموع & \\
\hline 12 & 10 & أقل من 30 سنة & \multirow[t]{4}{*}{ السن } \\
\hline 44.6 & 37 & من 30 إلى 40 سنة & \\
\hline 43.4 & 36 & أكثر من 40 سنة & \\
\hline 100 & 83 & المجموع & \\
\hline 13.3 & 11 & أقل من ثانوي & \multirow[t]{5}{*}{ المؤهل العلمي } \\
\hline 36.1 & 30 & ثانوي & \\
\hline 45.8 & 38 & جامعي & \\
\hline 4.8 & 4 & جامعي ما بعد التدرج & \\
\hline 100 & 83 & ألمجموع & \\
\hline 3.6 & 3 & وظيفة سامية & \multirow{7}{*}{ طبيعة الوظيفة } \\
\hline 8.4 & 7 & إطار سامي & \\
\hline 25.3 & 21 & إطار & \\
\hline 8.4 & 7 & التحكم & \\
\hline 36.1 & 30 & موظفو الخط الأمامي & \\
\hline 18.1 & 15 & منفذ & \\
\hline 100 & 83 & المجموع & \\
\hline 9.6 & 8 & أقل من 5 سنو ات & \multirow[t]{4}{*}{ سنوات العمل } \\
\hline 36.1 & 30 & من 5 إلى 10 سنوات & \\
\hline 54.2 & 45 & أكثر من 10 سنوات & \\
\hline 100 & 83 & المجموع & \\
\hline 2.4 & 2 & أقل من 18000 دج & الأجر \\
\hline
\end{tabular}




\begin{tabular}{|c|c|c|}
\hline 2.4 & 2 & من 18000 دج إلى 25000 دج \\
\hline 14.5 & 12 & من 25000 دج إلى 35000 دج \\
\hline 80.7 & 67 & أكثر من 35000 دج \\
\hline 100 & 83 & المجموع \\
\hline
\end{tabular}

المصدر: من إعداد الباحثة باستخدام SPSS

الجدول رقم (2): عرض آراء العينة حول متغيرات التسويق الداخلي

\begin{tabular}{|c|c|c|c|}
\hline الإنحريار اف & الحسابي & المتغير ات & 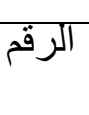 \\
\hline 1.19 & 2.66 & تختار المؤسسة الأفر اد ذوي الكفاءات و المهار ات العالية. & 01 \\
\hline 0.96 & $3 \cdot 82$ & هناك شعور بالر احة في المنصب الذي تشغله. & 02 \\
\hline $1 \cdot 21$ & $2 \cdot 85$ & لا تفكر في تغيير مكان عملك & 03 \\
\hline 1 1،07 & 3.42 & الاحتياجات التبرامج التديية. & 04 \\
\hline 1.02 & $2 \cdot 78$ & و القدف ات البراليةج لخدمة الزيبية اكتن. & 05 \\
\hline 1.08 & $2 \cdot 66$ & يساعد التدريب على تقديم خدمات للزبائن بجودة عالية. & 06 \\
\hline 0.95 & 3.66 & نظام الأجور المعتمد في المؤسسة جيد. & 07 \\
\hline 1 1.19 & $2 \cdot 73$ & بر امج الحو افز و المكافآَت يتناسب مع أداء العاملين. & 08 \\
\hline 0.95 & 4 4،14 & تعتمد المؤسسة على الحوافز المادية أكثر من الحوافز & 09 \\
\hline 1 1.18 & $2 \cdot 52$ & و المرية الاتصنال بين الموظفين والإدارة تمتاز بالسهولة & 10 \\
\hline 1 1.02 & 3.37 & الموظدين. المؤسسة على وسائل اتصال جيدة لتسهيل مهام & 11 \\
\hline 0.97 & 3.65 & وضوظي ودقة المعلومات الموجهة من الإدارة إلى & 12 \\
\hline 0.93 & 3.77 & تشجع المؤسسة تشكيل فرق عمل تتعاون فيما بينها. & 13 \\
\hline 1.07 & 3.48 & تتوفر صورة واضحة عن أولويات و أهداف المؤسسة. & 14 \\
\hline 0.97 & $3 ، 71$ & 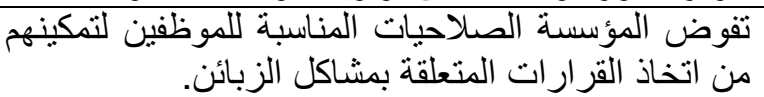 & 15 \\
\hline 1.07 & 3.33 & في ممارسة مهادهم العملية. فروس الإبداع و الابتكار للموظفين & 16 \\
\hline 0.94 & 03 & 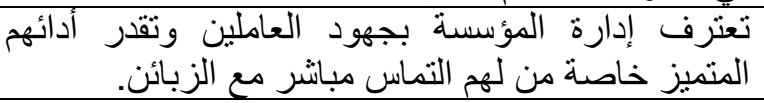 & 17 \\
\hline
\end{tabular}




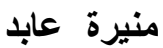

\begin{tabular}{|c|c|c|c|}
\hline 1.10 & 4.07 & تبمة للموظفين لايها. من خلال بر امج التسويق الداخلي إيجاد & 18 \\
\hline 1.18 & $2 \cdot 26$ & والموظفين. التسويق الداخلي على الحد من الصر اع بين الإدارة & 19 \\
\hline 1.01 & 2.32 & كما يجب. المؤسسة الوسائل والمعدات اللازمة لتأدية المهام & 20 \\
\hline
\end{tabular}

المصدر: من إعداد الباحثة باستخدام SPSS

جدول رقم 03: توزيع الوسط الحسابي والانحراف المعياري على محاور الاستبيان

\begin{tabular}{|c|c|c|c|c|c|c|}
\hline N6 & N5 & N4 & N3 & N2 & $\mathrm{N} 1$ & \\
\hline 3.62 & 3.95 & 3.16 & 3.13 & 2.82 & 2.94 & الوسط الحسابي \\
\hline 0.74 & 0.74 & 0.64 & 0.66 & 0.81 & 0.80 & المعياري الانحر \\
\hline
\end{tabular}

SPSS Sن إعداد الباحثة باستخدام 


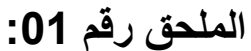 \\ الاستبيان}

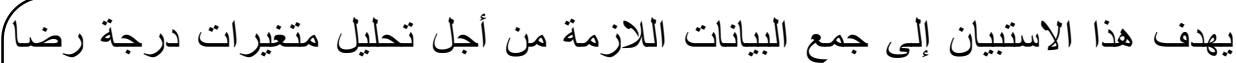

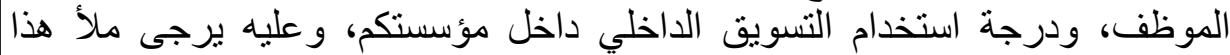

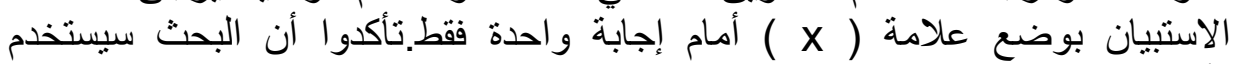
لأغراض البحث العلمي فقط شاكرين لكم حسن تعاونكم مسبقا

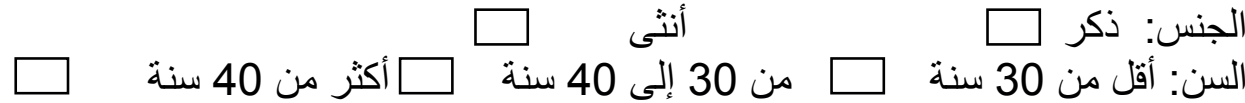

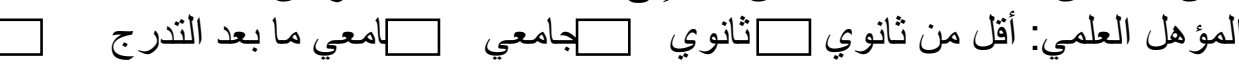

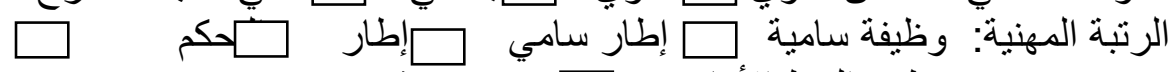
موظفي الخط الأمامي

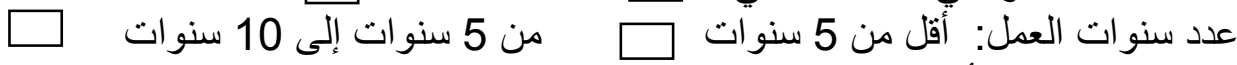
$\square \quad \square \quad$ أكثر من 10 سنوات

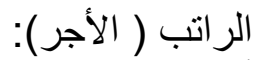
أقل من 18000.00دج (18000.00 إلى

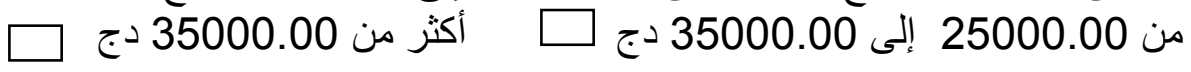

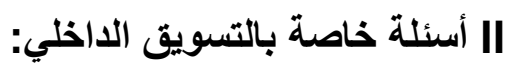

\begin{tabular}{|c|c|c|c|c|c|c|}
\hline 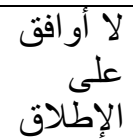 & 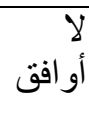 & محايد & مو افق & بشدة & متغيرات / أسئلة التسويق الاخلي & 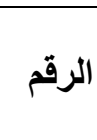 \\
\hline & & & & & 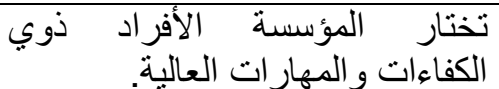 & 01 \\
\hline & & & & & هناك شعور بالر احة في المنصب & 02 \\
\hline
\end{tabular}


منيرة عابد

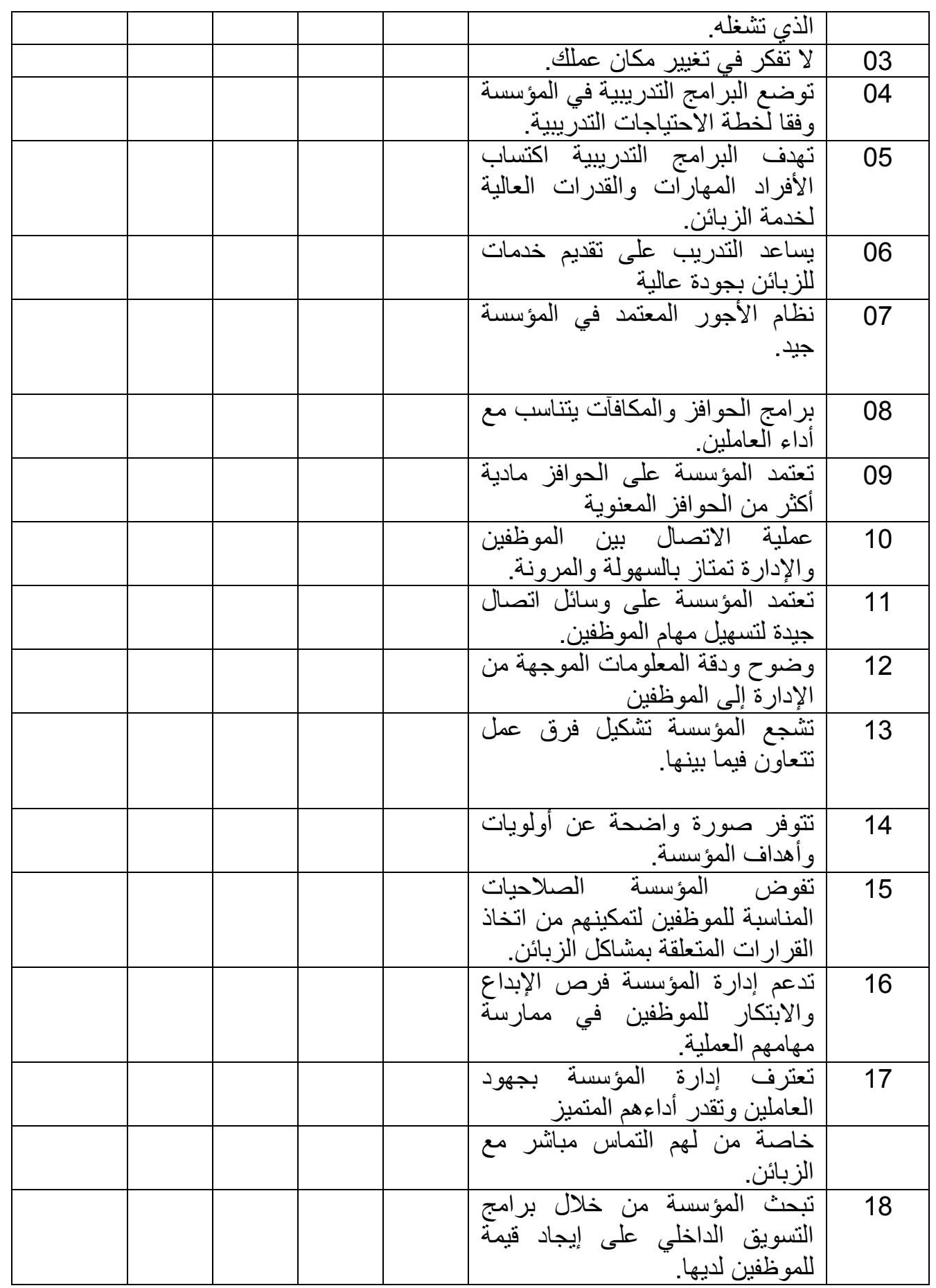




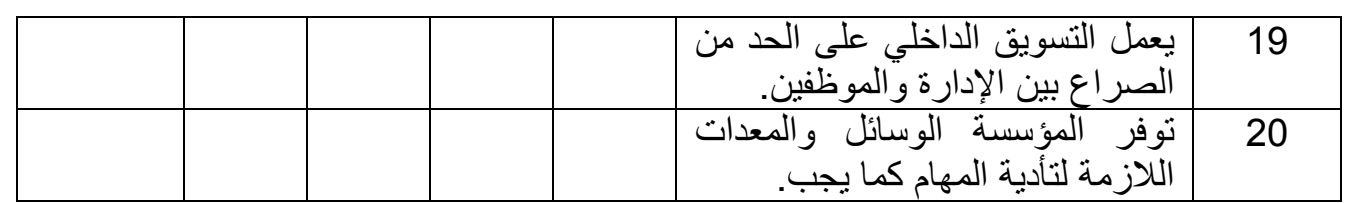

